OPEN ACCESS

Edited by: Bianca Marchetti, Università di Catania, Italy

Reviewed by:

Lu-Shiun Her, National Cheng Kung University, Taiwan

Francesco Fornai, University of Pisa, Italy

${ }^{*}$ Correspondence: Alessandra Stacchiotti alessandra.stacchiotti@unibs.it

Specialty section: This article was submitted to Signaling,

a section of the journal Frontiers in Cell and Developmental Biology

Received: 24 April 2020 Accepted: 01 September 2020 Published: 22 September 2020

Citation:

Stacchiotti A and Corsetti $G$ (2020) Natural Compounds and Autophagy: Allies Against Neurodegeneration Front. Cell Dev. Biol. 8:555409. doi: 10.3389/fcell.2020.555409

\section{Natural Compounds and Autophagy: Allies Against Neurodegeneration}

\author{
Alessandra Stacchiotti ${ }^{1,2 *}$ and Giovanni Corsetti ${ }^{1}$ \\ ${ }^{1}$ Division of Anatomy and Physiopathology, Department of Clinical and Experimental Sciences, University of Brescia, \\ Brescia, Italy, ${ }^{2}$ Interdepartmental University Center of Research "Adaptation and Regeneration of Tissues and Organs \\ (ARTO)," University of Brescia, Brescia, Italy
}

Prolonging the healthy life span and limiting neurological illness are imperative goals in gerontology. Age-related neurodegeneration is progressive and leads to severe diseases affecting motility, memory, cognitive function, and social life. To date, no effective treatments are available for neurodegeneration and irreversible neuronal loss. Bioactive phytochemicals could represent a natural alternative to ensure active aging and slow onset of neurodegenerative diseases in elderly patients. Autophagy or macroautophagy is an evolutionarily conserved clearing process that is needed to remove aggregateprone proteins and organelles in neurons and glia. It also is crucial in synaptic plasticity. Aberrant autophagy has a key role in aging and neurodegeneration. Recent evidence indicates that polyphenols like resveratrol and curcumin, flavonoids, like quercetin, polyamine, like spermidine and sugars, like trehalose, limit brain damage in vitro and in vivo. Their common mechanism of action leads to restoration of efficient autophagy by dismantling misfolded proteins and dysfunctional mitochondria. This review focuses on the role of dietary phytochemicals as modulators of autophagy to fight Alzheimer's and Parkinson's diseases, fronto-temporal dementia, amyotrophic lateral sclerosis, and psychiatric disorders. Currently, most studies have involved in vitro or preclinical animal models, and the therapeutic use of phytochemicals in patients remains limited.

\footnotetext{
Keywords: autophagy, polyphenols, alkaloids, terpenes, spermidine, trehalose, Alzheimer's disease, Parkinson's disease
}

\section{INTRODUCTION}

The mammalian central nervous system (CNS) is a crowded environment of highly specialized neurons surrounded by glial cells, fibroblasts, and pericytes, with smooth muscle cells and endothelial cells lining associated vessels (Stevens, 2003; Zeng and Sanes, 2017; Laredo et al., 2019; Matias et al., 2019). The unique post-mitotic nature of neurons, with scarce regenerative ability, means that they must have an efficient oxidative metabolism to support their specialized functions and resist cell death (Misgeld and Schwarz, 2017; Area-Gomez et al., 2018). Indeed, proper synapse function strongly depends on mitochondria, endoplasmic reticulum, lysosomes, and axonal flux of calcium ions and neurotransmitters (Wilhelm et al., 2014; Carmona-Gutierrez et al., 2016; Krols et al., 2016; Wu et al., 2017; Eisner et al., 2018). Primary inherited but also adult mitochondrial dysfunctions in neurons are not only linked to mtDNA or mtRNA changes but also to disrupted Krebs cycle, and related biochemical pathways up to reduced ATP availability. Therefore, altered morphology and signaling of crucial organelles, like mitochondria and lysosomes, dramatically 
initiate neurodegeneration (Lee et al., 2018; Cowan et al., 2019; Lie and Nixon, 2019) and vulnerable neurons' death (Andreone et al., 2019).

However, autophagy, literally from ancient Greek "selfeating," is an evolutionary conserved mechanism to maintain neuronal homeostasis during the development and in mature cells (Kulkarni et al., 2018). This "cleaning" pathway based on lysosomes' activity, maintains nutrient recycling in starvation, neurotransmitter release, synaptic remodeling and pruning during development in axons and dendrites (Geronimo-Olvera and Massieu, 2019; Lieberman and Sulzer, 2019; Lieberman et al., 2019; Stavoe and Holzbaur, 2019). Recently, Tomoda et al. (2019) outlined a novel essential role of autophagy, at synaptic level, regulating information processing, memory, mood, and cognitive functions in mouse models. Moreover, Lieberman et al. (2020) discovered another essential function of autophagy in the regulation of potassium channels in neurons in the striatum of mice, necessary for excitability and motor learning. However, autophagy is not only a peculiarity of neurons but also present in astrocytes, oligodendrocytes and microglia in aging and neurodegenerative disorders (Kim et al., 2017; Plaza-Zabala et al., 2017; Belgrad et al., 2020; Wang and Xu, 2020).

Since 2006, Mizushima's and Tanaka's group reported dysfunctional autophagy in mice lacking fundamental autophagy genes (ATG5 and ATG7 knockout) associated to locomotor abnormalities, neuronal loss in brain and cerebellum, behavioral defects and death within 28 weeks of birth (Hara et al., 2006; Komatsu et al., 2006).

Currently, the idea of a strict interdependence between autophagy and diseases in the CNS is well defined and aberrant autophagy is associated to aging and the pathogenesis of neurodegenerative diseases characterized by abnormal proteostasis (Morimoto and Cuervo, 2014; Tanaka and Matsuda, 2014; Nikoletopoulou et al., 2015). However, in addition to macroautophagy, other degradative mechanisms are involved in the clearance of misfolded proteins in neurons such as the molecular chaperones and the ubiquitin-proteasome (Nixon, 2013; Taylor et al., 2014; Ungelenk et al., 2016; Cristofani et al., 2017; Mogk and Bukau, 2017). Recent evidence indicates that chaperones and ubiquitin-proteasome are mainly required to dismantle short-lived soluble proteins, while autophagy dismantles large misfolded aggregates in non-selective or selective manner (Chu, 2019). This last mechanism, called aggrephagy, implies a receptor and a substrate connection to best recognize abnormal inclusions in damaged neurons (Gatica et al., 2018). Indeed, toxic proteic aggregates impair neurotransmission, calcium flux, mitochondria activity, membrane permeability and are commonly detected in animals and post-mortem brain in patients affected by neurodegenerative diseases like Alzheimer's (AD), Parkinson's (PD), amyotrophic lateral sclerosis (ALS), frontotemporal dementia (FTD), and Huntington's (HD) (Chung et al., 2018; Cheon et al., 2019; Malampati et al., 2020). However, in addition to protein aggregates, selective autophagy removes damaged organelles like mitochondria, ribosomes and the endoplasmic reticulum to maintain neuronal homeostasis (Morishita and Mizushima, 2019; Evans and Holzbaur, 2020).
Consequently, there is extensive evidence that dysfunctional autophagy and/or mitophagy have been implicated in the onset and progression of neurodegenerative and psychiatric disorders like bipolar disorder and schizophrenia (Fujikake et al., 2018; Mizushima, 2018; Bar-Yosef et al., 2019; Kuang et al., 2019; Malik et al., 2019; Palikaras and Tavernarakis, 2020).

In recent years, the belief that autophagy is a druggable target and, consequently, its modulation a promising therapeutic opportunity for CNS diseases have been reported in several authoritative reviews (Morel et al., 2017; Scrivo et al., 2018; Condello et al., 2019; Djajadikerta et al., 2019; Mputhia et al., 2019; Peng et al., 2019; Thellung et al., 2019). However, the complex pathogenesis of neurodegeneration and a better knowledge of autophagy steps and upstream signaling pathways are necessary to extend promising results obtained in animal models to patients. Remarkably, autophagy modulation seems particularly favorable in an early phase of neurodegeneration and long-term autophagy modulators without side effects are urgently required (Li et al., 2015; Menzies et al., 2017; Giampieri et al., 2019).

For all these reasons, we conceived this critical review focusing on recent studies on dietary natural products and herbs able to regulate autophagy and limit neurodegeneration in vitro, in rodent models and eventually in patients. Before analyzing the specific role of natural products in neurodegenerative diseases, a brief explanation of the autophagic mechanisms activated in the brain is shown below.

\section{AUTOPHAGIC SIGNALING}

There are three crucial types of autophagy deeply characterized in neurons (Bento-Cuesta et al., 2017) and less in glia (Strohm and Behrends, 2019), defined macroautophagy, chaperone-mediated autophagy (CMA) and endosomal microautophagy.

\section{Macroautophagy}

Macroautophagy (simply referred as "autophagy" hereafter), the most studied dynamic mechanism of recycling macromolecules and organelles, may be beneficial or detrimental for neurons, depending on its intensity, speed (called "the autophagic flux") and regulation (Feng et al., 2014; Button et al., 2015; Hansen et al., 2018). Indeed, there is a basal beneficial autophagy necessary for proper development to maintain life span and prolong longevity, and a detrimental excessive autophagy, called autophagic cell death or autosis (Galluzzi et al., 2018). This last type is predominant in the hippocampus, where the loss of adult stem neurons, consequent to insulin withdrawal, induces cognitive deficits (Yu et al., 2008; Jung et al., 2020). Moreover, also selected autophagy of mitochondria, called mitophagy, whenever excessive becomes detrimental leading to neuronal death, such as reported in ischemic and hypoxic events in vitro and in rat spinal cord (Feng et al., 2018; Yu et al., 2018). Recent studies in preclinical animal models and in post-mortem brain samples from patients indicated a strict connection between defective autophagy and mitophagy to the pathogenesis of Parkinson's 
(Gao et al., 2017; Arotcarena et al., 2019; Lin et al., 2019) and Alzheimer's disease (Chakravorthy et al., 2019; Xie et al., 2020).

However, it is essential to precisely modulate and monitor each step of the autophagy process to avoid detrimental irreversible effects instead of benefits in neurons (Mariňo et al., 2011). Therefore, we resumed below different stages of mammalian autophagy, considering that for each step it is possible to foresee a genetic or a pharmacologic regulation.

The first step of autophagy starts in the cytoplasm with the "phagophore," a peculiar double membrane that subsequently elongates, and closes on itself to produce an "autophagosome," filled with misfolded proteins, lipidic materials or damaged organelles. The "autophagosome" progressively matures and merges with lysosomes becoming an "autolysosome" to complete clearing. In the last final step, all cargo is dismantled by lysosomal hydrolases and eventually a new phagophore is reformed.

Different upstream machineries control the induction of mammalian autophagy and the first initiation step. The most studied are the serine/threonine protein kinase ULK1 (unc51-like kinase 1), which forms an assembly with autophagyrelated proteins 13 and 101 (Zachari and Gauley, 2017), and phosphatidylinositol 3-kinase (PI3K), essential for starting all the process (Devereaux et al., 2013). The following elongation step involves a detailed genetic program and autophagy-related proteins (ATGs), directly regulated by two pathways: the mTOR complex 1 (mTORC1) and Bcl2/Beclin 1 , the mammalian ortholog of ATG6. Intriguingly, mTORC1 downregulates ULK1, so inhibiting autophagy, but may be further positively regulated by Akt or negatively by the AMPactivated protein kinase (AMPK). In this last case, autophagy is stimulated. Other kinases regulate Bcl2 by inhibiting its binding to Beclin 1 and stimulating autophagy ( $\mathrm{He}$ and Klionsky, 2009). Furthermore, selected transcription factors influence the formation of autophagosomes, like the master transcriptional regulator of autophagy/lysosomal biogenesis (TFEB), and peroxisome proliferator-activated receptor alpha (PPAR alpha) (Fullgrabe et al., 2016). Remarkably, to treat devastating neurodegenerative syndromes many efforts have been addressed to modulate TFEB and, consequently, to restore proper autophagy (Cortes and La Spada, 2019).

Different set of ATG proteins regulate the maturation and the closure of the autophagosome, and mainly the ATG8/LC3, or microtubule-associated protein 1 light-chain 3 (LC3I), is necessary for the final formation of the autophagic vacuole. Indeed, for this step, the cytosolic LC3I become lipidated and associated with phosphatidylethanolamine to generate LC3II linked to the autophagosomal membrane (Mizushima, 2018). The final degradation of the cargo involves the fusion with lysosomes, strictly dependent on the sequestosome (SQSTM1 or p62) protein, that is a reliable marker of an effective autophagic flux (Sanchez-Martin and Komatsu, 2018).

Mitophagy, the selective autophagy of mitochondria, requires specific receptors, able to select damaged mitochondria for the removal (Gatica et al., 2018). The most studied are PTENkinase 1 (PINK1) and Parkin. PINK1, located in the outer mitochondrial membrane, recruits parkin, an ubiquitin ligase, from the cytoplasm to the depolarized mitochondria, making them recognizable by the autophagosome for dismantling. Altered PINK1/parkin signaling in dopaminergic neurons has been strictly associated to the pathogenesis of PD (Truban et al., 2017; Lin et al., 2019; Noda et al., 2020), and defective mitophagy is an additional hallmark of AD, FTD and ALS diseases (Cai and Jeong, 2020; Xie et al., 2020). Recent evidence indicates in autosomal recessive PD the recruitment of PINK1 to mitochondria-associated membrane (MAM) and the regulation of mitochondria-ER distance and mitophagy (Gelmetti et al., 2017). Intriguingly, an abnormal tethering and consequent disrupted mitophagy have been described in long projecting axon neurons and glia in ALS (BernardMarissal et al., 2018). Curiously, mice lacking PINK1 or Parkin do not present severe PD evidences like neuronal loss or locomotor dysfunctions, typical of humans, but probably due to their limited life span (Evans and Holzbaur, 2020). However, in hypoxia, different mitophagy pathways driven by novel receptors like NIX (Nip3 like protein X)/BNIP3 (Bcl2/adenovirus E1B $19 \mathrm{kDa}$ protein-interacting protein 3) or FUNDC1 (FUN14 domain containing 1) are activated. Recently, in mutant dopaminergic neurons, an in vitro model of PD, Ryan et al. (2018) demonstrated that cardiolipin exposure in the outer mitochondrial membrane is necessary for activating mitophagy and refolding of toxic alpha synuclein. Remarkably, all above receptors joined LC3 or gammaaminobutyric acid receptor-associated protein (GABARAP) on the autophagosome for final mitochondria dismantling (Palikaras et al., 2018). A resumptive plot indicating the progressive macroautophagy signaling and its regulation is shown in Figure 1.

\section{Chaperone-Mediated Autophagy (CMA)}

Compared to macroautophagy, chaperone-mediated autophagy (CMA) presents three fundamental peculiarities: it removes only misfolded cytoplasmic proteins and not organelles; it does not require mature autophagosomes but only lysosomes; the recognition of aggregated proteins and the targeting to lysosomes are performed by a cytosolic chaperone HSC70 (Kaushik and Cuervo, 2018). For proper dismantling, all cytosolic proteins must contain an amino acidic sequence related to KFERQ. The complex obtained is then up-taken by the lysosome-associated membrane glycoprotein 2 (LAMP2) and degraded. Failure in CMA has been detected in PD to dismantle abnormal alpha-synuclein aggregates (a favorite CMA substrate), but alsoin $\mathrm{AD}, \mathrm{TD}$ and $\mathrm{HD}$ to remove excessive tau protein, TAR DNA-binding protein 43 (TDP-43) and huntingtin protein, respectively (Martinez-Vicente et al., 2010; Cuervo and Wong, 2014; Wu et al., 2015; Tripathi et al., 2019). For these reasons, targeting CMA can be considered another therapeutic opportunity if autophagy is unresponsive (Xilouri et al., 2013). Intriguingly, two pathways modulate CMA in neurons: mTORC2 that inhibits LAMP2A assembly and lysosomal p38 MAPK during ER stress response (Li et al., 2019). Indeed, CMA pathway works together with other homeostatic mechanism like the ER stress response and reduced interaction between these processes results in loss of dopaminergic neurons in the substantia nigra in mice (Li 


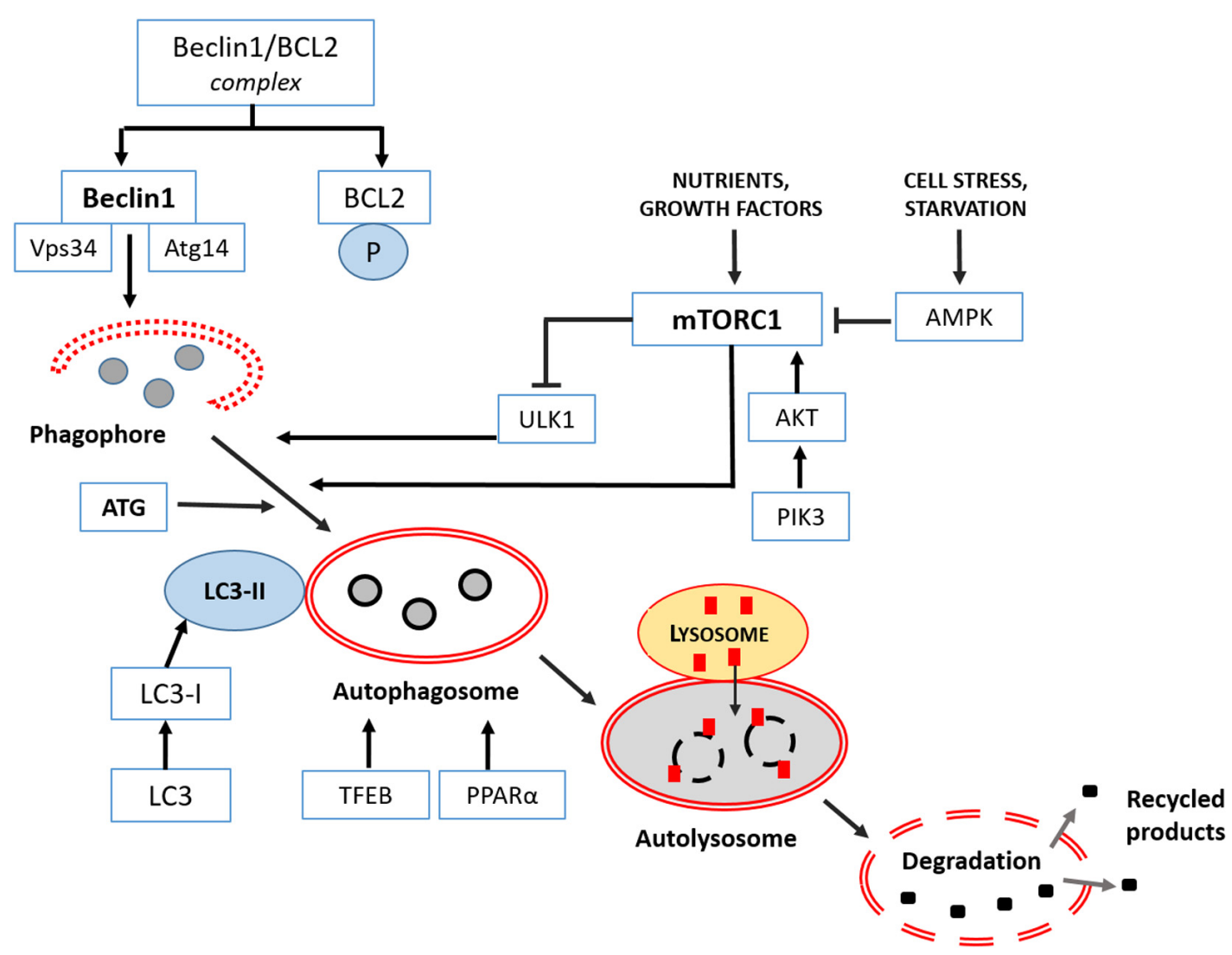

FIGURE 1 | Macroautophagy signaling in the mammalian brain. It consists in three main phases: formation-elongation of a round structure, maturation then its content degradation-recycling. The first step of autophagy starts in the cytoplasm with the "phagophore," a peculiar double membrane structure derived from ER, Golgi complex or plasmalemma that subsequently elongates, and closes on itself to produce an "autophagosome," filled with proteins or lipidic material and damaged organelles. Then the "autophagosome" progressively matures and merges with lysosomes becoming an "autolysosome" or "amphisome"to complete clearing. In the last final step, all cargo is dismantled by acidic lysosomal hydrolases and eventually a new phagophore is reformed. Major regulators of different phases are class III PI3-K complex and Beclin 1 protein, Atg proteins cascade resulting in Atg3/Atg7 mediated LC3I into LC3II conversion as indicated and discussed in the text. Extensive details on macroautophagy machinery are reported by Feng et al. (2014).

et al., 2017). Conversely, proper restoration of both CMA and macroautophagy, by the upstream regulation of the nuclear erythroid 2-related factor 2 (Nrf2) in astrocytes, promotes effective alpha-synuclein degradation and rescue in a PD mice model (Gan et al., 2012).

\section{Microautophagy}

This mechanism, still poorly defined in mammalians, involves the direct recruitment of cytosolic proteins containing the sequence KFERQ via Hsc70 into a membrane invagination of a late endosome or lysosome then their full degradation (Malik et al., 2019). This peculiar autophagosome-independent transfer occurred at synaptic level and was necessary for the renovation of synaptic proteins. Sato et al. (2019) reported that rapamycin, a known activator of macroautophagy, stimulated microautophagy in cells by TFEB stimulation and hypothesized its involvement in neurodegenerative diseases. The delivery of proteins to be degraded within vesicles resembled a "secretory autophagy" mechanism and intraluminal exosomes formation (Buratta et al., 2020).

\section{NUTRACEUTICALS EFFECTIVE IN NEURODEGENERATION VIA AUTOPHAGY}

Chronic neurodegenerative diseases are untreatable and few approved synthetic drugs reduced adverse symptoms but not cure them. In this discouraging scenario, oral supplementation with vegetal bioactive derivatives or the Mediterranean diet are promising to postpone the irreversible progression of $\mathrm{AD}, \mathrm{PD}$, ALS, FTD (Vauzour et al., 2017; Hornedo-Ortega et al., 2018; Pohl and Lin, 2018; Fernandez-Sanz et al., 2019).

However, considering that the relation "one-drug, one-target" for the multifactorial pathogenesis of neurodegenerative diseases is clinically unsuccessful, traditional medicinal herbs or plants with beneficial pleiotropic effects may represent a plausible preventive auxiliary therapeutic opportunity (Cummings et al., 2014; Park et al., 2018; Di Paolo et al., 2019). Plants derived compounds or "nutraceuticals" are secondary metabolites, produced by the plants to defend themselves from pathogens or adverse environmental conditions and have been proposed as 
complementary "herbal Medicine" to treat Alzheimer's (AD) and Parkinson's disease (PD) (Ahn and Jeon, 2015; Perez-Hernandez et al., 2016; Naoi et al., 2019; Renaud and Martinoli, 2019; Chiu et al., 2020).

Nutraceuticals are largely present in fruit, vegetables, cereals, herbs used in the human nutrition, with pleiotropic antioxidant, anti-inflammatory, glycemia-regulating properties able to preserve brain (Kennedy and Wightman, 2011; Gonzalez et al., 2019) with fewer side-effects than synthetic drugs (Georgiou et al., 2011; Forni et al., 2019). Recently, an important source of neuroprotective compounds like phytosterols, carotenoids, fucoidans and polyphenols have been characterized also in seaweeds consumed in China and Indonesia (Schepers et al., 2020). Most of them are effective anti-inflammatory and antioxidants and preserve dendritic spine density in hippocampal neurons. However, the harvest and purification of seaweeds are crucial to obtain bioactive compounds to use at a dosage effective for the brain activity.

Considering the pathogenetic role of aberrant autophagy in neurodegenerative diseases, emerging evidence indicates that nutraceuticals modulators of autophagy may be promising "functional foods" (Fan et al., 2017; Prieto-Dominguez et al., 2018; Xie et al., 2019; Zeng et al., 2019). Moreover, autophagy and mitophagy are involved in the removal of aggregated proteins and dysfunctional mitochondria hallmark of $\mathrm{AD}, \mathrm{PD}$, frontotemporal dementia (FTD) and Huntington disease (HD) (Menzies et al., 2017).

In the following subheadings, we discussed and commented studies published in the last decade on nutraceuticals as regulators of autophagy and their role in neurodegenerative diseases. Natural compounds have been subdivided according to their chemical structure into four categories: polyphenols, alkaloids, terpenes and terpenoids. Finally, the last subheading, entitled "Others", is dedicated to chemically heterogeneous compounds that are emerging against neurodegeneration and aging, like the pineal indole melatonin, the disaccharide trehalose and the polyamine spermidine, a well-known caloric restriction mimetic (Kiechl et al., 2018; Lee et al., 2018; Madeo et al., 2019).

\section{Polyphenols}

Phenolics compounds are commonly present in human diet, due to their large presence in plants. They derived from phenylalanine and contained almost one phenol ring that contributed to different subclasses like: phenols acids, flavonoids, stilbenes and lignans (Tsao, 2010). Compounds belonging to this category deeply involved to attenuate neurodegeneration are: polyphenols like resveratrol in wine and in virgin olive oil; flavanols in cocoa, tea, apples, beans; hydroxycinnamates in coffee; flavonoids in tea, apples, onions, chocolate; anthocyanins in berries (Angeloni et al., 2017; Potì et al., 2019). The effects of polyphenols on autophagy are rapidly emerging as specific to a single step of the process for each neurodegenerative syndrome (Kou and Chen, 2017).

Resveratrol (3,5,4'-trihydroxy-trans-stilbene), largely present in plants and in red wine as derivative from Vitis viniferas, regulated AMPK/mTORC1 pathway and activated the first step of autophagy to alleviate cognitive impairment in $\mathrm{AD}$ mice.
However, dysfunctional enhanced autophagy has been reported as pathogenic hallmark of $\mathrm{AD}$ in dystrophic neurites with autophagic vacuoles, upregulated mTOR and reduced Beclin 1 (Pickford et al., 2008; Lipinski et al., 2010; Bordi et al., 2016). All these studies highlighted the controversial role of autophagy in AD (Castellazzi et al., 2019) and its dependence on neuronal topology and on the stage of cognitive impairment (Liu and Li, 2019).

In a recent proteomic study Lachance et al. (2019) reported in post-mortem brain reduced gene expression for autophagy kinase complex in the para-hippocampal area and hippocampus. Remarkably, the same evidence occurs in mice deprived of BECN1-PIK3C3 complex that showed memory deficits and impaired autophagy. Conversely, the activation of the nuclear receptor binding factor 2 (NRBF2), associated to PI3K complex, greatly influenced autophagy flux progression and demolition of toxic amyloid aggregates (Yang C. et al., 2017). Recently, Reddy and Oliver (2019) reported reduced autophagy and mitophagy caused by excessive amyloidosis and tau deposition in $\mathrm{AD}$. Other authors reported that resveratrol is effective to reduce abnormal beta amyloid deposition in APP/PS1 mice activating AMPK (Di Meco et al., 2020) and sustaining Beclin 1 and LC3II via a Sirtuin1 signaling. Remarkably, its low bioavailability and difficulty to cross the brain blood barrier must be taken in account for its pharmacological efficacy (Salehi et al., 2018). In fact, only the trans isoform is effective in the hippocampus of $\mathrm{AD}$ mice by sustaining autophagy (Porquet et al., 2014). In vitro, in PC12 cells, resveratrol promoted autophagy via Sirtuin 1 protein and subsequent LC3I deacetylation (Deng and Mi, 2016). Resveratrol rescued ischemic damage in the rat brain during middle cerebral artery occlusion or excitotoxicity induced by glutamine (Pineda-Ramirez et al., 2020). In these models the stilbene stimulated mitophagy by activation of AMPK, Beclin 1 and LC3II conversion. Resveratrol potentiated motoneuron recovery and decreased apoptosis, after spinal cord injury in mice, through promotion of Beclin 1, LC3II and autophagy (Hu et al., 2017). Similar results were reported by Wang P. et al. (2018) in rat spinal cord injury, where resveratrol activated AMPK and autophagic flux, and consequently inhibited mTOR pathway, and in vitro in PC12 cells. Moreover, resveratrol induced autophagy, in dopaminergic SH-SY5Y cells challenged with rotenone via haeme oxygenase signaling (Lin et al., 2014).

As for PD mouse model triggered by methyl-4-phenyl1, 2, 3, 6-tetrahydropyridine (MTP), resveratrol ameliorated locomotor activity and the number of dopaminergic neurons in the substantia nigra pars compacta, promoting Sirtuin 1/ LC3II and reducing p62/SQSTM (Guo et al., 2016). Sirtuin 1 was crucial to maintain tolerance to neurotoxic aggregates in $\mathrm{AD}$ and $\mathrm{PD}$ by inhibiting mTOR and promoting autophagy (Lee, 2019). Finally, resveratrol restored ATG4 and stimulated LC3 II and autophagy in neuroblastoma SH-SY5Y cells expressing mutant-Huntingtin treated by dopamine (Vidoni et al., 2018).

Curcumin, the main active component of curry spices, and curcuminoid from Curcuma longa plants have been reported to induce autophagy in $\mathrm{AD}$ mice limiting mTOR/Akt signaling and sustaining LC3 (Wang C. et al., 2014; Shakeri et al., 2019; Voulgaropoulou et al., 2019). Curcumin protected in vitro 
an AD neuronal cell model (N2a/APP695swe), enhancing a retrograde axonal flux and restoring autophagy via Beclin 1 (Liang et al., 2019). Similarly, solid lipid nanoparticles driving curcumin stimulated CMA in human neuroblastoma cells and in mice neuronal cells challenged with toxic beta-amyloid inducing molecular chaperones and lysosomal activity (Maiti et al., 2017). Unfortunately, despite benefits in experimental animal models (Perrone et al., 2019), the clinical efficacy of curcuminoids in AD is still controversial (Zholos et al., 2019). However, due to the strong ability of curcumin to bind $\beta$-amyloid fibrils, it has been successfully adopted as fluorescent biomarker in the retinas at early stages of $\mathrm{AD}$ in patients and mice (Koronyo-Hamaoui et al., 2011). Intriguingly, Zhang et al. (2018) demonstrated that curcumin protected hippocampal neurons in amyloid treated mouse by limiting abnormal Beclin 1 and autophagosomes formation. Curcumin was also effective in PD in vitro model of dopaminergic neurons where modulated autophagy and cleaned $\alpha$-synuclein aggregates (Jaroonwitchawan et al., 2017; Li et al., 2017). Moreover, a curcumin analog compound stimulated autophagy via TFEB-lysosome signaling, independently of mTOR, in murine neuroblastoma cells and in vivo (Song et al., 2016).

Green tea cathechins, mainly epigallocatechin gallate (EGCG) from Camelia sinensis, are diffuse phenols with recognized multiple antioxidant, anti-inflammatory and neuroprotective properties, activating beclin 1, autophagy and mitophagy as reviewed by Prasanth et al. (2019).

Phenolic oleosides, in particular oleuropein aglycone (OLE) from Olea europea, are safe antiaging, antioxidants and neuroprotective substances present in extra virgin olive oil (Casamenti et al., 2015). OLE supplementation for 3 months to the diet is able to sustain autophagy, at the last step of fusion of autophagosomes and lysosomes, so ameliorating cortical neuronal damage in transgenic $\mathrm{AD}$ and PD mice (Lauretti et al., 2017). Rigacci et al. (2015) demonstrated that OLE, in vitro to neuroblastoma cells and in AD TgRND8 mice, was able to intensify autophagy via calcium release from sarcoplasmic reticulum, activation of calmodulin-dependent kinase kinase $\beta$ (CAMKK $\beta$ ) and AMPK but mTOR inhibition. Intriguingly, OLE is a pleiotropic molecule able to regulate sirtuins and consequently Atg genes activation in AD mice (Cordero et al., 2018). Recently, Al Rihani et al. (2019) reported that extra virgin olive oil derivatives are able to cross the brain blood barrier, to reduce inflammation, amyloidosis and plaques in $\mathrm{AD}$ mice via AMPK signaling and autophagy restoration. Moreover, OLE, tested in PC12 cells exposed to a parkinsonian toxin, reduced mitochondrial damage and accelerated autophagic flux, so reducing neuronal death (Achour et al., 2016).

Phenolic pomegranate extracts, added in vitro to dopaminergic SH-SY5Y cells, upregulated autophagy and mitophagy after toxic challenge. Remarkably, the mechanism of mitophagy involved the recruitment of PINK1 and parkin to mitochondria during chemical stress (Tan et al., 2019).

Phenolic bacosides, active biocomponents from Bacopa monnieri, were effective to reduce ROS production and lipofuscin aggregation but preserved mitochondria in aged rats. Furthermore, they ameliorated cognitive ability and memory in humans in health and AD (Manap et al., 2019) even their influence on autophagy has not been studied yet.

Flavonoids like quercetin coupled to nanoparticles, silibinin and wogonin have been successfully used in vitro in SH-SY5Y neurons, and in vivo in rodent and human $\mathrm{AD}$, where they induced autophagy by ULK1/mTOR, beclin 1 production and clearing amyloid substance (Wang D. et al., 2014; Ashrafizadeh et al., 2019b; Liu et al., 2019; Zhang et al., 2020). Silymarin, a lignan extracted from seeds of Silibum marianum, has been employed as anti-inflammatory and anti-oxidative agent in stroke by transient forebrain ischemia in rat. The neuroprotection by silymarin was due to reduced autophagic death in the CA1 region of the hippocampus (Hirayama et al., 2016). Baicalein, another flavonoid from Scutellaria baicalensis, protected rotenone treated neuroblastoma cells and mice, a well-known PD model, promoting autophagy and preventing mitochondrial damage (Kuang et al., 2017).

\section{Alkaloids}

Alkaloids are neuroprotective agents extracted by different plants and herbs, such as Solanacee, Papaveracee, Ranuncolacee, Amaryllidacee (Hussain et al., 2018).

Berberine, an alkaloid derived from Berberis species herbs, ameliorated autophagic flux and removed tau aggregates in AD mice, recovering memory and spatial learning (Chen et al., 2020). Intriguingly, it was also effective in removal of abnormal ubiquitinated TDP-43 deposits in frontotemporal degeneration (FTD) and amyotrophic lateral sclerosis (ALS) by autophagy (Ling et al., 2013; Chang et al., 2016). Moreover, berberine attenuated neuronal damage in a spinal cord injury model in mice, by triggering autophagy in oligodendrocytes (Wang et al., 2017). Berberine has also an important anti-cancer effect in glioblastoma by activating autophagy via AMPK signaling decreased glycolytic activity and invasive potential of cells (Chang et al., 2016; Wang et al., 2016). Oral berberine enhanced life span and stimulated autophagic markers in the brain and cerebellum of transgenic N171-82Q mice, a HD model (Jiang et al., 2015).

Caffeine, one of the most common alkaloids in the world, modulated autophagy in SH-SY5Y neuroblastoma cells exposed to prion derived protein, so protecting them against apoptosis (Moon et al., 2014). Recently, Luan et al. (2018) demonstrated that caffeine, supplemented in drinking water for 120 days, in PD mice triggered autophagy and CMA enhancing LC3 and LAMP2 and reversing toxic $\alpha$-synuclein deposits.

Conophylline, an alkaloid derived from Ervatamia microphylla, similarly stimulated autophagy in vitro neurons in HD and PD mimetic models (Sasazawa et al., 2015; Umezawa et al., 2018).

Dendrobium nobile, an alkaloid derivative from Orchidacee very common in China, has been recently demonstrated to protect hippocampal neurons exposed to $\beta$-amyloid by promoting Beclin 1 and accelerating autophagic flux (Li et al., 2017).

\section{Terpenes and Terpenoids}

Terpenes extracted by essential aromatic oils have a recognized anti-inflammatory and antioxidant role (Quintans et al., 2019). 
Monotherpenes have been recently considered also modulators of autophagy (Ashrafizadeh et al., 2019a).

Bergamot essential oil from Citrus bergamot and its derived terpene, D-limonene, have been successfully added in vitro to human neuroblastoma cells SH-SY5Y where they induced autophagy, increasing LC3II, and accelerated autophagic flux but independently from Beclin1 (Russo et al., 2014).

Cubeben, a sesquiterpene from Piper cubeba, reduced beta amyloid toxicity in vitro in primary neuronal cells recovering autophagy via PI3K/AMPK signaling and inhibiting mTOR (Li et al., 2019a).

Ginaton, an extract from Ginko biloba leaves, is a mixture of terpenoids, flavonoids and organic acids with pleiotropic roles as antioxidative and neuroprotective product, mainly after $4 \mathrm{~h}$ after brain ischemia in stroke (Tian et al., 2017). Li et al. (2019b) induced ischemic stroke in rats, by middle cerebral artery occlusion, and treated animals with ginaton $24 \mathrm{~h}$ after reperfusion once a day for 14 days. Neurological symptoms ameliorated and the infarct site decreased, together with enhanced autophagic markers via AMPK and inhibition of apoptosis.

Geraniol, an acyclic monotherpene present in several aromatic plants, was effective to protect neurons from rotenone stress, an in vitro PD model, by recovering mitochondria and decreasing $\alpha$-synuclein and improving autophagic flux (Rekha and Sivakamasundari, 2018).

Cucurbitacin E, a terpenoid phytosterol from Ecballium elaterium (Cucurbitacee), partially protected PC12 neurons, treated with toxins to simulate $\mathrm{PD}$, but remarkably, reduced Beclin 1 autophagy, and ameliorated autophagosomes necessary for dismantling toxic deposits (Arel-Dubeau et al., 2014).

Carotenoids, known also as tetraterpenoids, are common bioactive pigments present in fruits and vegetables in the human diet, such as peach, watermelon, tomato, spinach, carrots, broccoli, and seaweeds with antioxidant and anti-inflammatory activities, useful against neurodegeneration (Cho et al., 2018). Fucoxanthin, a carotenoid from brown seaweeds, has been an

TABLE 1 | Nutraceuticals effective against neurodegeneration via autophagy in vitro.

\begin{tabular}{|c|c|c|c|}
\hline Nutraceuticals & Disease model & Dose/Signaling & References \\
\hline \multicolumn{4}{|l|}{ Polyphenols } \\
\hline \multirow[t]{4}{*}{ Resveratrol } & $A D-A \beta 25-35$ treated $P C 12$ & $20 \mu \mathrm{M}$ - Increased PARP1-SIRT1 & $\begin{array}{l}\text { Lin et al., 2014; Deng and Mi, 2016; Guo } \\
\text { et al., 2016; Vidoni et al., 2018; } \\
\text { Pineda-Ramirez et al., } 2020\end{array}$ \\
\hline & PD-Rotenone treated SH-SY5Y & $20 \mu \mathrm{M}$-Increased Heme oxygenase & \\
\hline & HD-Dopamine treated SH-SY5Y & $100 \mu \mathrm{M}$-ATG4-LC3 activity & \\
\hline & Glutamate-treated neurons & 30 нM-AMPK-LC3 & \\
\hline Pomegranate extract & PD-SH-SY5Y & $\begin{array}{l}300 \mu \mathrm{g} / \mathrm{ml} \text { for } 6 \text { and } 24 \mathrm{~h} \text { - TFEB activation } \\
\text { for mitochondrial quality control. }\end{array}$ & Tan et al., 2019 \\
\hline \multirow[t]{2}{*}{ Curcumin } & $\begin{array}{l}\text { AD-N2a/APP695swe AD-hippocampal } \\
\text { neurons }\end{array}$ & 1-10 $\mu \mathrm{M}$-TFEB binding & $\begin{array}{l}\text { Wang C. et al., 2014; Song et al., 2016; Li } \\
\text { et al., 2017; Zhang et al., 2018; Liang et al., } \\
\text { 2019; Zholos et al., } 2019\end{array}$ \\
\hline & PD-primary neurons & $\begin{array}{l}50 \mu \mathrm{M} \text {-AMPK activation;10-12 M-Restored } \\
\text { autophagic flux }\end{array}$ & \\
\hline \multirow[t]{2}{*}{ Oleuropein aglycone } & AD-SH-SY5Y & $\begin{array}{l}50 \mu \mathrm{M} \text { for } 4 \text { h-Free } \mathrm{Ca}^{2+} \\
\text { flux-CAMKK } \beta \text {-AMPK activation }\end{array}$ & Rigacci et al., 2015 \\
\hline & PD-PC12 cells & $10^{-12} \mathrm{M}$ for $3 \mathrm{~h}$ - Activated autophagic flux & Achour et al., 2016 \\
\hline \multicolumn{4}{|l|}{ Flavonoids } \\
\hline Quercetin & AD-SH-SY5Y & $\begin{array}{l}5 \mathrm{mg} / \mathrm{ml} \text { gold-palladium nanoparticles for } \\
24 \mathrm{~h} \text {-Enhanced autophagosomes }\end{array}$ & Ashrafizadeh et al., 2019b \\
\hline Baicalein & PD-Rotenone treated SH-SY5Y & $10 \mu \mathrm{M}$ for $24 \mathrm{~h}$-activated LC3 & Kuang et al., 2017 \\
\hline \multicolumn{4}{|l|}{ Alkaloids } \\
\hline Caffeine & Prion treated-SH-SY5Y cells & 2-8 mM-LC3II induction & Moon et al., 2014 \\
\hline Conophylline & $\mathrm{HD}$ and PD-PC12 neurons & $3.5 \mathrm{ng} / \mathrm{ml}$ - Enhanced autophagic flux & Umezawa et al., 2018 \\
\hline Dendrobine & AD-A $\beta$ hippocampus neurons & $\begin{array}{l}10^{-8} \mathrm{M} / \mathrm{L} \text { for } 24 \mathrm{~h}-\mathrm{LC} 3 \mathrm{II} \text {, enhanced } \\
\text { autophagic flux }\end{array}$ & Li et al., 2017 \\
\hline \multicolumn{4}{|l|}{ Terpenes } \\
\hline D-Limonene & Starved SH-SY5Y & $\begin{array}{l}0.005-0.3 \%-L C 3 \| \text { and autophagic flux } \\
\text { activation }\end{array}$ & Russo et al., 2014 \\
\hline Cubeben & $A D-A \beta$ neurons & 5-20 $\mu \mathrm{M}$ for $48 \mathrm{~h}$-Inhibition of PI3K/Akt & Li et al., 2019a \\
\hline Geraniol & PD-Rotenone treated SK-N-SH cells & 100 nM for 24 h-Increased Atg5-7-12 & Rekha and Sivakamasundari, 2018 \\
\hline Cucurbitacin E & PD- PC12 neurons & $\begin{array}{l}\text { 10-10 M-regulated autophagy-lysosomal } \\
\text { pathway }\end{array}$ & Arel-Dubeau et al., 2014 \\
\hline \multicolumn{4}{|l|}{ Others } \\
\hline$\beta$-Asarone & AD-PC12 neurons & 24-72 $\mu \mathrm{M}$-LC3II -Beclin 1 induction & Wang et al., 2020 \\
\hline Melatonin & Senescent SH-SY5Y & $\begin{array}{l}1 \mu \mathrm{M} \mathrm{L}-1 \text { - Beclin 1-autophagic flux } \\
\text { activation }\end{array}$ & Nopparat et al., 2017 \\
\hline Trehalose & NSC34 cells & $\begin{array}{l}100 \text { mM for } 24 \text { h-TFEB activation/Akt } \\
\text { inhibition }\end{array}$ & Rusmini et al., 2019 \\
\hline
\end{tabular}


activator of main autophagic markers, and a neuroprotector in mice model of traumatic brain injury via Nrf2 pathway (Zhang et al., 2017).

\section{Others}

Spermidine, a safe polyamine present in several seeds and plantbased food, like soy and wheat germ (Muñoz-Esparza et al., 2019), prolongs lifespan in lower organisms like flies, yeast and worms, and ameliorate cognitive ability in mice and old humans (Schwarz et al., 2018). Moreover, in addition to induce autophagy by removing inhibitory acetyltransferase EP300 (Pietrocola et al., 2015), spermidine was an anti-inflammatory drug that alleviated experimental autoimmune encephalomyelitis in mice (Yang Q. et al., 2016).

Beta-asarone (cis-2,4,5-trimethoxy-1-allyl-phenyl), a volatile oil from Acorus tatarinowi herb, has been successfully tested in an AD model in PC12 neurons challenged with amyloid (A $\beta 42)$, the toxic protein in plaques. Both autophagy, the autophagic flux and mitophagy pathways were triggered and ameliorated by this compound in a dose dependent manner (Wang et al., 2020). However, if in vitro this product sustained Beclin 1 and LC3II signaling, the same markers were inhibited in vivo in double transgenic APP/PS1 mice and autophagosomes decreased in hippocampal neurons (Deng et al., 2016). Probably, in vivo autophagy was not the main mechanism targeted by beta-asarone able to ameliorate memory and learning in mice.

Melatonin, the pineal indole, also present in vegetal food, seeds and fruit, has been considered a powerful anti-inflammatory and antioxidant dietary supplement in neurodegeneration (Shukla et al., 2019). Melatonin intake reduced experimental subarachnoid hemorrhage $(\mathrm{SAH})$ in rats by blocking neuronal apoptosis and abnormal autophagy just $2 \mathrm{~h}$ post SAH (Shi et al., 2018). Moreover, melatonin sustained Parkin/PINK1 pathway and mitophagy but inhibited inflammasome in the same animal model (Cao et al., 2017). Similarly, in vitro in senescent SHSY5Y cells, melatonin was a potent autophagy inducer and

TABLE 2 | Nutraceuticals effective against neurodegeneration via autophagy in vivo.

\section{Nutraceuticals}

Polyphenols

Resveratrol

Disease model

AD-A $\beta P P / P S 1$ mice

Brain ischemia rat

Spinal cord injury rat and mice

PD-MPTP mice

Curcumin

AD-APP/PS1 mice

Traumatic brain injury-rat

Oleuropein aglycone

AD-TgCRND8 mice PD mice

Flavonoids

Quercetin

AD-PD mice

Traumatic brain injury-rat

Silymarin

Baicalein

Alkaloids

Berberine

Caffeine

Terpenes

Ginaton

Carotenoids

Others

$\beta$-Asarone

Melatonin

Trehalose
Forebrain ischemia-rat

PD-Rotenone injected mice

$A D$ and $H D$ mice

Spinal cord injury-rat

PD mice

Brain ischemia mice

Traumatic brain injury mice

AD-APP/PS1 mice

$\mathrm{SAH}$ rats

Batten disease mice
Dose/Signaling

$1 \%$ for 10 months-AMPK/Sirtuin

$1.8 \mathrm{mg} / \mathrm{kg}$ - AMPK/Beclin1

200 mg/kg/day i.p. for 3 days-LKB1/AMPK

$100 \mathrm{mg} / \mathrm{kg} /$ day for 33 days-Sirtuin 1-LC3

160-1000 ppm for 6

months-Downregulated PIK3Akt/mTOR

25-100 mg/kg-Enhanced Beclin 1, LC3

$5 \mathrm{mg} / \mathrm{kg}$ diet for 8 weeks-AMPK activation, mTOR inhibition EVOO-rich diet for 6 months-Atg5-Atg7-AMPK

$5 \mathrm{mg} / \mathrm{kg} /$ day for 4 weeks

$50 \mathrm{mg} / \mathrm{kg}$ i.p. for 12-24h

$7 \mathrm{mg} / \mathrm{kg}$-reduced autophagic flux

100 mg/kg i.p. for 5 weeks-LC3 activation

$40 \mathrm{mg} / \mathrm{kg}$-Akt inhibition

$20 \mathrm{mg} / \mathrm{kg}$-AMPK activation

$1 \mathrm{~g} / \mathrm{L}$ for 3 months-LC3II-LAMP2A

activation

$50 \mathrm{mg} / \mathrm{kg}$ for 14 days-AMPK activation

50-200 mg/kg i.g.-Beclin 1-LC3 activation

$10 \mathrm{mg} / \mathrm{kg}$-Beclin 1-Akt reduction

5-10 mg/kg i.v.-abnormal autophagy

decrease

$2 \%$ oral-TFEB activation
References

Porquet et al., 2014; Guo et al., 2016; Hu et al., 2017; Zhao et al., 2017; Wang P. et al., 2018; Vidoni et al., 2018;

Pineda-Ramirez et al., 2020

Wang C. et al., 2014; Song et al., 2016;

Gao et al., 2017; Li et al., 2017

Achour et al., 2016; Lauretti et al., 2017; Cordero et al., 2018;

Rigacci et al., 2015; Al Rihani et al., 2019

Ashrafizadeh et al., 2019b; Liu et al., 2019; Zhang et al., 2020

Hirayama et al., 2016

Kuang et al., 2017

Jiang et al., 2015; Wang et al., 2017.

Chen et al., 2020

Luan et al., 2018

Tian et al., 2017; Li et al., 2019b

Zhang et al., 2017

Deng et al., 2016

Cao et al., 2017; Shi et al., 2018

He et al., 2016; Holler et al., 2016; Tien et al., 2016; Palmieri et al., 2017

AD, PD, FTD mice 
an antagonist of NF-kB signaling by sirtuin 1 deacetylase (Nopparat et al., 2017).

Trehalose, a disaccharide present in bacteria, yeast, fungi and plants but not in vertebrates, has caught the attention as an autophagic regulator in neurodegenerative diseases (Khalifeh et al., 2019). Palmieri et al. (2017) demonstrated that trehalose, administered to a mice model of Batten disease (a neurodegenerative lysosomal disease), stimulated the clearance of toxic aggregates via activation of TFEB, the fundamental regulator of lysosomal pathway. In $\mathrm{AD}, \mathrm{PD}$ and frontotemporal dementia models, the disaccharide destroyed misfolded proteins and triggered an efficient autophagic flux and lysosomal activity (He et al., 2016; Holler et al., 2016; Tien et al., 2016). Conversely, other studies on transgenic $\mathrm{AD}$ mice and on alpha-synuclein challenged neuroblastoma cells and primary rat cortical neurons, reported a protective activity but independent from autophagy or a block of the final step of autophagy and autolysosomes formation (Portbury et al., 2017; Yoon et al., 2017; Lee et al., 2018). A recent study on immortalized motoneurons demonstrated that trehalose induced TFEB nuclear translocation and autophagy and that TFEB silencing counteracted its effect (Rusmini et al., 2019). Unfortunately, trehalose cannot be assumed orally in humans because degraded by trehalase, an enzyme present in the gastrointestinal tract. However, recently nanolipid-trehalose conjugated have been developed as effective autophagy inducers to overcome the poor pharmacokinetics of this sugar and its efficacy at higher doses (Colombo et al., 2019).

To recapitulate, the signaling of nutraceuticals driving autophagy in vitro or in rodent models of CNS diseases are shown in Tables 1, 2, respectively.

\section{NON-SPECIFIC EFFECTS OF NUTRACEUTICALS IN NEURODEGENERATION}

The majority of nutraceuticals reported here has been selected for their effects on the macroautophagy machinery in experimental neurodegenerative models. However, it is important to emphasize that their activity is non specific, because the same compound has multiple roles and may act as an anti-aging, anti-apoptotic, free radicals-scavenger or anti-inflammatory drug (Howes et al., 2020). For example, ferulic acid, a phenolic compound commonly present in fruits and vegetables, orally administered at $80-100 \mathrm{mg} / \mathrm{kg}$ in rats $30 \mathrm{~min}$ before middle cerebral artery occlusion, limits ischemia reducing apoptosis and activating autophagy (Cheng et al., 2019). Conversely, crocin, a flavonoid from Crocus and Gardenia species, ameliorated memory and behavior in $\mathrm{AD}$ rat model, reducing apoptosis and citochrome c release but was ineffective on autophagic markers beclin 1/LC3 (Asadi et al., 2015). Moreover, not only a single natural principle but often mixed formulation of components may be adopted in experimental and clinical trials. For example, sailuotong, a mixture of saffron from Crocus sativus, Ginkgo biloba, and Panax ginseng, has been tested successfully in old adults, with mild cognitive impairment, to ameliorate cognitive abilities (Steiner et al., 2018). The synergistic effect of berberine and curcumin was more potent than the single compound to improve cognitive function after 3 months of treatment in $\mathrm{AD}$ mice (Lin et al., 2020). Extra virgin olive oil, a mixture of polyphenols, $\alpha$ and $\gamma$-tocopherols, added for 6 months to the diet in a taupathy mice model, alleviated synaptic activity in the hippocampus and memory impairment (Lauretti et al., 2020). Currently, more intense pharmacological and pharmacokinetic studies are required to ameliorate safety, purity, bioavailability of nutraceuticals, together with the urgent requirement of a unique worldwide regulation (Helal et al., 2019).

\section{CONCLUSION}

This review focused on the regulatory role of natural dietary compounds on autophagy to postpone or alleviate neurodegeneration in vitro and in animal models. Unfortunately, major knowledge on the defective autophagy in humans is urgent to successfully treat patients. The importance of preventive or therapeutic autophagy regulation in neurodegenerative diseases is still debated (Bar-Yosef et al., 2019; Maiuri and Kroemer, 2019; Park et al., 2020; Suomi and Mc Williams, 2020). Negrete-Hurtado et al. (2020) reported in ATG5 KO mice brain, a non canonical role of ATG proteins and that lipidation machinery is not required for neuronal survival. Indeed, the main function of ATG-induced LC3 lipidation is to regulate microtubular dynamic in en passant boutons. According to this study, to enhance autophagy may be deleterious in forebrain axons, affecting retrograde flux and function.

Nevertheless, there is wide consensus on the efficacy of natural pleiotropic compounds able to enhance or restored insufficient autophagy in aggregated-prone proteins pathologies like $\mathrm{AD}, \mathrm{PD}, \mathrm{HD}$ in preclinical rodent models (Djajadikerta et al., 2019; Rahman et al., 2020). Remarkably, it is clear that the neuronal damage, the intensity and stage of disease greatly condition the beneficial or detrimental use of nutraceuticals and autophagy tuning in brain injury and aging (Galluzzi et al., 2017; Yessenkyzy et al., 2020). Therefore, it must be remembered that autophagy can be a double-sided process. Ferrucci et al. (2018) critically indicated that there was not a unique beneficial role of autophagy in the hypoxic brain and that may be better to inhibit autophagy to alleviate chronic ischemia. For this reason, nutraceuticals like Leonurine, an active extract from Leonorus cardiaca, inhibited ATG pathways and autophagy, so reducing neuronal damage (Liu et al., 2016).

Moreover, neurodegenerative diseases are multifactorial and many pathways must be considered (Kuang et al., 2019). Therefore, not only autophagy but also necrosis and apoptosis contributed to neuronal cell death (Leong et al., 2020). Remarkably, natural compounds able to limit neurodegeneration in vitro might not be effective in vivo and multiple products are suggested both natural and synthetic (Mazzanti and Di Giacomo, 2016). Moreover, different types of autophagy, reciprocally regulated, might concur 
to alleviate abnormal proteins deposition and to clear organelles in neurons (Wang H. et al., 2018; Oshima et al., 2019; Cai and Jeong, 2020). Recently, Mizushima (2018) claimed that to measure autophagic flux in humans is still impossible and consequently the direct analysis of the efficacy of natural drugs on autophagy is lacking, due to the absence of adequate quantitative methods. However, we are confident that new discoveries on autophagy tuning in the brain may confirm the utility of safe bioactive compounds and their importance to prevent or limit unavoidable neurodegeneration. Major advances in our understanding of their mechanisms of action and pharmacokinetic and nonspecific effects are necessary for success in the struggle against neurodegenerative disorders.

\section{REFERENCES}

Achour, I., Arel-Dubeau, A., Renaud, J., Legrand, M., Attard, E., Germain, M., et al. (2016). Oleuropein prevents neuronal death, mitigates mitochondrial superoxide production and modulates autophagy in a dopaminergic cellular model. Int. J. Mol. Sci. 17:1293. doi: 10.3390/ijms17081293

Ahn, T., and Jeon, B. (2015). The role of quercetin on the survival of neuronlike PC12 cells and the expression of $\alpha$-synuclein. Neurol. Regener. Res. 10, 1113-1119. doi: 10.4103/1673-5374.160106

Al Rihani, S., Darakjian, L., and Kaddoumi, A. (2019). Oleocanthal-rich extravirgin olive oil restores the blood-brain barrier function through NLRP3 inflammasome inhibition simultaneously with autophagy induction in TgSwDI mice. ACS Chem. Neurosci. 10, 3543-3554. doi: 10.1021/acscheneuro.9b00175

Andreone, B., Larhammar, M., and Lewcock, J. (2019). Cell death and Neurodegeneration. Cold Spring Harb. Perspect. Biol. 12:a036434. doi: 10.1101/ cshperspect

Angeloni, C., Malaguti, M., Bartalace, M., and Hrelia, S. (2017). Bioactivity of olive oil phenols in neuroprotection. Int. J. Mol. Sci. 18:2230. doi: 10.3390/ ijmss 18112230

Area-Gomez, E., de Groof, A., Bonilla, E., Montesinos, J., Tanji, K., Boldogh, I., et al. (2018). A key role for MAM in mediating mitochondrial dysfunction in Alzheimer disease. Cell Death Dis. 9:335. doi: 10.1038/S41419-017-0215-0

Arel-Dubeau, A., Longprè, F., Bournival, J., Tremblay, C., Demers-Lamarche, J., Haskova, P., et al. (2014). Cucurbitacin E has neuroprotective properties and autophagic modulating activities on dopaminergic neurons. Oxid. Med. Cell. Longev. 2014:425496. doi: 10.1155/2014/425496

Arotcarena, M., Teil, M., and Dehay, B. (2019). Autophagy in synucleinopathy: the overwhelmed, and defective machinery. Cells 8:565. doi: 10.3390/cells8060565

Asadi, F., Jamshidi, A., Khodagholi, F., Yans, A., Azimi, L., Faizi, M., et al. (2015). Reversal effects of crocin on amyloid $\beta$-induced memory deficit: Modification of autophagy or apoptosis marke. Pharmacol. Biochem. Behav. 139, 47-58. doi: 10.1016/j.pbb.2015.10.011

Ashrafizadeh, M., Ahmadi, Z., Farkhondeh, T., and Samarghandian, S. (2019a). Autophagy as a molecular target of quercetin underlying its protective effects in human diseases. Arch. Physiol. Biochem. 28, 1-9. doi: 10.1080/13813455.2019. 1671458

Ashrafizadeh, M., Ahmadi, Z., Mohammadineiad, R., Kavivani, N., and Tavakol, S. (2019b). Monoterpenes modulating autophagy: A review study. Basic. Clin. Pharmacol. Toxicol. 126:31237736. doi: 10.111/bcpt.13282

Bar-Yosef, T., Damri, O., and Agam, G. (2019). Dual role of autophagy in diseases of the central nervous system. Front. Cell. Neurosci. 13:196. doi: 10.3389/fncel. 2019.00196

Belgrad, J., De Pace, R., and Fields, R. (2020). Autophagy in myelinating glia. J. Neurosc. 40, 256-266. doi: 10.1523/JNEUROSCI.1066-19.2019

Bento-Cuesta, I., Diez, H., Ordoňez, L., and Wandosell, F. (2017). Assessment of autophagy in neurons and brain tissue. Cells 6:25. doi: 10.3390/cells6030025

Bernard-Marissal, N., Chrast, R., and Schneider, B. (2018). Endoplasmic reticulum and mitochondria in diseases of motor and sensory neurons: a broken relationship? Cell Death Dis. 9:333. doi: 10.1038/s41419-017-0125-1

\section{AUTHOR CONTRIBUTIONS}

AS wrote the manuscript and, Tables 1, 2. GC provided revised Figure 1 and reviewed the text. Both authors conceptualized the topic, discussed the literature data, approved the final revised version of the manuscript, and ensured the accuracy of the work and intellectual content. A professional service revised the whole text in English.

\section{FUNDING}

This study has been supported by the local funds (ex 60\% 20192020) to AS.

Bordi, M., Berg, M., Mohan, P., Peterhoff, C., Alldred, M., Che, S., et al. (2016). Autophagic flux in CA1 neurons of Alzheimer hippocampus increased induction overburdens failing lysosomes to propel neuritic dystrophy. Autophagy 12, 2467-2483. doi: 10.1080/15548627.2016.1239009

Buratta, S., Tancini, B., Sagini, K., Delo, F., Chiaradia, E., Urbanelli, L., et al. (2020). Lysosomal exocytosis, exosome release and secretory autophagy: The autophagic- and endo-lysosomal systems go extracellular. Int. J. Mol. Sci. 21:2576. doi: 10.3390/ijms21072576

Button, R., Luo, S., and Rubinsztein, D. (2015). Autophagic activity in neuronal cell death. Neurosci. Bull. 31, 382-394. doi: 10.1007/s12264-015-1528-y

Cai, Q., and Jeong, Y. (2020). Mitophagy in Alzheimer's disease and other agerelated neurodegenerative diseases. Cells 9:150. doi: 10.3390/cells9010150

Cao, S., Shrestha, S., Li, J., Yu, X., Chen, J., Yan, F., et al. (2017). Melatoninmediated mitophagy protects against early brain injury after sub-arachnoid hemorrage through inhibition of NLRP3 inflammasome activation. Sci. Rep. 7:2417. doi: 10.1038/s41598-017-02679

Carmona-Gutierrez, D., Hughes, A., Madeo, F., and Ruckenstuhl, C. (2016). The crucial impact of lysosomes in aging and longevity. Ageing Res. Rev. 32, 2-12. doi: 10.1016/j.arr.2016.04.009

Casamenti, F., Grossi, C., Rigacci, S., Pantano, D., Luccarini, I., and Stefani, M. (2015). Oleuropein aglycone: a possible drug against degenerative conditions. In vivo evidence of its effectiveness against Alzheimer's disease. J. Alzheimers Dis. 45, 679-688. doi: 10.3233/JAD- 142850

Castellazzi, M., Patergnani, S., Donadio, M., Giorgi, C., Bonora, M., Bosi, M., et al. (2019). Autophagy and mitophagy biomarkers are reduced in sera of patients with Alzheimer's disease and mild cognitive impairment. Sci. Rep. 9:20009. doi: 10.1038/s41598-019-56614-5

Chakravorthy, A., Jetto, C., and Manjithaya, R. (2019). Dysfunctional mitochondria and mitophagy as drivers of Alzheimer's disease pathogenesis. Front. Aging Neurosci. 11:311. doi: 10.3389/fnagi.2019.00311

Chang, C., Lee, Y., Lee, K., Lin, H., Chen, C., and Shen, C. (2016). Therapeutic effect of berberine on TDP-43 related pathogenesis in FTLD and ALS. J. Biomed. Sci. 23:72. doi: 10.1186/s12929-016-0290-z

Chen, Y., Chen, Y., Liang, Y., Hongda, C., Ji, X., and Huang, M. (2020). Berberine mitigates cognitive decline in an Alzheimer's disease mouse model by targeting tau hyperphosphorylation and autophagic clearance. Biomed. Pharmacol. 121:109670. doi: 10.1016/j.biopha.2019.109670

Cheng, C., Kao, S., and Lee, Y. (2019). Ferulic acid exerts anti-apoptotic effects against ischemic injury by activating $\mathrm{HSP} 70 / \mathrm{Bcl} 2$ and HSP70/autophagy mediated signaling after permanent focal cerebral ischemia in rats. Am. J. Chinese Med. 47, 39-61. doi: 10.1142/s0192415X19500034

Cheon, S., Kim, H., Rubinsztein, D., and Lee, J. (2019). Autophagy, cellular aging and age-related human diseases. Exp. Neurobiol. 28, 643-657. doi: 10.5607/en. 2019.28.6.643

Chiu, H., Venkatakrishnan, K., and Wang, C. (2020). The role of nutraceuticals as complementary therapy against various neurodegenerative diseases: a mini review. J. Trad. Compl. Med. 10, 434-439. doi: 10.1016/j.cm.2020.03.008

Cho, K., Shin, M., Kim, S., and Lee, S. (2018). Recent advances in studies on the therapeutic potential of dietary carotenoids in neurodegenerative 
diseases. Oxid. Med. Cell. Longev. 2018:4120458. doi: 10.1155/2018/412 0458

Chu, T. (2019). Mechanisms of selective autophagy and mitophagy: Implications for neurodegenerative diseases. Neurobiol. Dis. 122C, 23-34. doi: 10.1016/j. nbd.2018.07.015

Chung, C., Lee, H., and Lee, S. (2018). Mechanisms of protein toxicity in neurodegenerative diseases. Cell. Mol. Life Sci. 75, 3159-3180. doi: 10.1007/ s00018-018-2854-4

Colombo, E., Biocotino, M., Frapporti, G., Randazzo, P., Christodoulou, M., Piccoli, G., et al. (2019). Nanolipid-trehalose conjugates and nanoassemblies as putative autophagy inducers. Pharmaceutics 11:422. doi: 10.3390/ pharmaceutics 11080422

Condello, M., Pellegrini, E., Caraglia, M., and Meschini, S. (2019). Targeting autophagy to overcome human diseases. Int. J. Mol. Sci. 20, E725. doi: 10.3390/ ijms 20030725

Cordero, J., Garcia-Escudero, R., Avila, J., Gargini, R., and Garcia-Escudero, V. (2018). Benefit of oleuropein aglycone for Alzheimer's disease by promoting autophagy. Oxid. Med. Cell Longev. 2018:5010741. doi: 10.1155/2018/5010741

Cortes, C., and La Spada, A. (2019). TFEB dysregulation as a driver of autophagy dysfunction in neurodegenerative disease: Molecular mechanisms, cellular processes, and emerging therapeutic opportunities. Neurobiol. Dis. 122, 83-93. doi: 10.1016/j.nbd.2018.05.012

Cowan, K., Anichtchik, O., and Luo, S. (2019). Mitochondrial integrity in neurodegeneration. CNS Neurosc. Therap. 25, 825-836. doi: 10.1111/cns.13105

Cristofani, R., Crippa, V., Rusmini, P., Cicardi, M., Meroni, M., Licata, N., et al. (2017). Inhibition of retrograde transport modulates misfolded protein accumulation and clearance in motoneuron diseases. Autophagy 13, 1280-1303. doi: 10.1080/15548627.2017.1308985

Cuervo, A., and Wong, E. (2014). Chaperone-mediated autophagy: roles in disease and aging. Cell Res. 24, 92-104. doi: 10.1038/cr.2013.153

Cummings, J., Morstorf, T., and Zhong, K. (2014). Alzheimer's disease drugdevelopment pipeline: Few candidates, frequent failure. Alzheimers Res. Ther. 6:37. doi: $10.1186 /$ alzrt269

Deng, H., and Mi, M. (2016). Resveratrol attenuates A-beta 25-35 caused neurotoxicity by inducing autophagy through the TyrRS-PARP1-SIRT1 signaling pathway. Neurochem. Res. 41, 2367-2379. doi: 10.1007/s11064-0161950-9

Deng, M., Huang, L., Ning, N., Wang, N., Zhang, Q., Zhu, C., et al. (2016). $\beta$ asarone improves learning and memory and reduces acetyl cholinesterase and beta-amyloid 42 levels in APP/PS1 transgenic mice by regulating Beclin-1dependent autophagy. Brain Res. 1652, 188-194. doi: 10.1016/j.brainres.2016. 10.008

Devereaux, K., Dall'Armi, C., Alcazar-Roman, A., Ogasawara, Y., Zhou, X., Wang, F., et al. (2013). Regulation of mammalian autophagy by class II and class III PI3-kinases through PI3P synthesis. PLoS One 8:e76405. doi: 10.1371/journal. pone. 0076405

Di Meco, A., Curtis, M., Lauretti, E., and Pratico', D. (2020). Autophagy dysfunction in Alzheimer's disease: mechanistic insights and new therapeutic opportunities. Biol. Psych. 87, 797-807. doi: 10.1016/j.biopsych.2019.05.008

Di Paolo, M., Papi, L., Gori, F., and Turillazzi, E. (2019). Natural products in neurodegenerative diseases: A great promise but an ethical challenge. Int. J. Mol. Sci. 20:5170. doi: 10.3390/ijms20205170

Djajadikerta, A., Keshri, S., Pavel, M., Prestil, R., Ryan, L., and Rubinsztein, D. (2019). Autophagy induction as a therapeutic strategy for neurodegenerative diseases. J. Mol. Biol. 432, 2799-2821. doi: 10.1016/j.jmb.2019.12.035

Du, G., Zhao, Z., Chen, Y., Li, Z., Tian, Y., Liu, Z., et al. (2016). Quercetin attenuates neuronal autophagy and apoptosis in rat traumatic brain injury model via activation of PI3K/Akt signaling pathway. Neurol. Res. 38, 1012-1019. doi: 10.1080/016412.2016.1240393

Eisner, V., Picard, M., and Hajnoczky, G. (2018). Mitochondrial dynamics in adaptive and maladaptive cellular stress responses. Nat. Cell Biol. 20, 755-765. doi: 10.1038/s41556-018-0133-0

Evans, C., and Holzbaur, E. (2020). Quality control in neurons: mitophagy and other selective autophagy mechanisms. J. Mol. Biol. 432, 240-260. doi: 10.1016/ j.jmb.2019.06.031

Fan, Y., Wang, N., Rocchi, A., Zhang, W., and Vassar, R. (2017). Identification of natural products with neuronal and metabolic benefits through autophagy induction. Autophagy 13, 41-56. doi: 10.1080/15548627.2016.1240855
Feng, J., Chen, X., Guan, B., Li, C., Qiu, J., and Shun, J. (2018). Inhibition of peroxinitrite-induced mitophagy activation attenuates cerebral ischemiareperfusion injury. Mol. Neurobiol. 8, 6369-6678. doi: 10.1007/s12035-0170859-x

Feng, Y., He, D., Yao, Z., and Klionsky, D. (2014). The machinery of macroautophagy. Cell Res. 24, 24-41. doi: 10.1038/cr.2013.168

Fernandez-Sanz, P., Ruiz-Gabarre, D., and Garcia-Escudero, V. (2019). Modulating effect of diet on Alzheimer's disease. Diseases 7:12. doi: $10.3390 /$ diseases7010012

Ferrucci, M., Biagioni, F., Ryskalin, L., Limanagi, F., Gambardella, S., Frati, A., et al. (2018). Ambiguous effects of autophagy activation following hypoperfusion/ischemia. Int. J. Mol. Sci. 19:2756. doi: 10.3390/ijms 19092756

Forni, C., Facchiano, F., Bartoli, M., Pieretti, S., Facchiano, A., D'Arcangelo, D., et al. (2019). Beneficial role of phytochemicals on oxidative stress and agerelated diseases. BioMed. Res. Int. 2019:8748253. doi: 10.1155/2019/8748253

Fujikake, N., Shin, M., and Shimizu, S. (2018). Association between autophagy and neurodegenerative diseases. Front. Neurosci. 12:255. doi: 10.3389/fnins.2018. 00255

Fullgrabe, J., Ghislat, G., Cho, D., and Rubinstein, D. (2016). Transcriptional regulation of mammalian autophagy at a glance. J. Cell Sci. 129, 3059-3066. doi: $10.1242 /$ jcs. 188920

Galluzzi, L., Bravo-San Pedro, J., Levine, B., Green, D., and Kroemer, G. (2017). Pharmacological modulation of autophagy: therapeutic potential and persisting obstacles. Nat. Rev. Drug Discov. 16, 487-511. doi: 10.1038/nrd.2017.22

Galluzzi, L., Vitale, I., Aaronson, S., Abrams, J., Adam, D., Agostinis, P., et al. (2018). Molecular mechanisms of cell death: reccomandations of the Nomenclature Committee on cell death. Cell Death Diff. 25, 486-541. doi: 10.1038/s41418-017-0012-4

Gan, L., Vargas, M., Johnson, D., and Johnson, J. (2012). Astrocyte-specific overexpression of Nrf2 delays motor pathology and synuclein aggregation throughout the CNS in the alpha-synuclein mutant (A53T) mouse model. J. Neurosci. 32, 17775-17787. doi: 10.1523/JNEUROSCI.3049-12.2012

Gao, F., Yang, J., Wang, D., Li, C., Fu, Y., Wang, H., et al. (2017). Mitophagy in Parkinson's disease: pathogenesis and therapeutic implications. Front. Neurol. 8:527. doi: 10.3389/fneur.2017.00527

Gao, Y., Zhuang, Z., Gao, S., Li, X., Zhang, Z., Ye, Z., et al. (2017). Tetrahydrocumarin reduces oxidative stress-induced apoptosis via the mitochondrial apoptotic pathway by modulating autophagy in rats after traumatic brain injury. Am. J. Transl. Res. 9, 887-899.

Gatica, D., Lahiri, V., and Klionsky, D. (2018). Cargo recognition and degradation by selective autophagy. Nat. Cell Biol. 20, 233-242. doi: 10.1038/s41556-0180037-z

Gelmetti, V., De Rosa, P., Torosantucci, L., Marini, E., Romagnoli, A., Di Rienzo, M., et al. (2017). PINK1 and BECN1 relocalize at mitochondria-associated membranes during mitophagy and promote ER-mitochondria tethering and autophagosome formation. Autophagy 13, 654-669. doi: 10.1080/15548627. 2016.1277309

Georgiou, N., Garssen, J., and Witkamp, R. (2011). Pharma-nutrition interface: the gap is narrowing. Eur. J. Pharmacol. 651, 1-8. doi: 10.1016/j.ejphar.2010.11.007

Geronimo-Olvera, C., and Massieu, L. (2019). Autophagy as a homeostatic mechanism in response to stress conditions in the central nervous system. Mol. Neurobiol. 56, 6594-6608. doi: 10.1007/s12035-019-1546-x

Giampieri, F., Afrin, S., Forbes-Hernandez, T., Gasparrini, M., Cianciosi, D., Reboredo-Rodriguez, P., et al. (2019). Autophagy in human health and disease: novel therapeutic opportunities. Antiox. Redox Signal. 30, 577-634. doi: 10. 1089/ars.2017.7234

Gonzalez, I., Morales, M., and Rojas, A. (2019). Polyphenols and AGEs/RAGE axis. Trends Chall. Food Res. Int. 129:108843. doi: 10.1016/j.foodres.2019.108843

Guo, Y., Dong, S., Cui, X., Feng, Y., Liu, T., Yin, M., et al. (2016). Resveratrol alleviates MPTP-induced motor impairment and pathological changes by autophagic degradation of $\alpha$-synuclein via SIRT1-deacetylated LC3. Mol. Nutr. Food Res. 60, 2161-2175. doi: 10.1002/mnfr.201600111

Hansen, M., Rubinzstein, D., and Walker, D. (2018). Autophagy as a promoter of longevity: insights from model organisms. Nat. Mol. Cell Biol. 19, 579-593. doi: 10.1038/s41580-018-0033-y

Hara, T., Nakamura, K., Matsui, M., Yamamoto, A., Nakahara, Y., SuzukiMigishima, R., et al. (2006). Suppression of basal autophagy in neuronal cells 
causes neurodegenerative disease in mice. Nature 441, 885-889. doi: 10.1038/ nature 04724

He, C., and Klionsky, D. (2009). Regulation mechanisms and signaling pathways of autophagy. Ann. Rev. Genet. 43, 67-93. doi: 10.1146/annurev-genet-102808114910

He, Q., Koprich, J., Wang, Y., Yu, W., Xiao, B., Brotchie, J., et al. (2016). Treatment with trehalose prevents behavioural and neurochemical deficits produced in an AAV alpha-synuclein rat model of Parkinson's disease. Mol. Neurobiol. 53, 2258-2268. doi: 10.1007/s12035-015-9173-7

Helal, N., Eassa, H., Amer, A., Eltokhy, M., Edaiogho, I., and Nounon, M. (2019). Nutraceuticals'novel formulations: the good, the bad, the unknown and patents. Recent Pat. Drug Deliv. Formul. 13, 105-156. doi: 10.2174/ 1872211313666190503112040

Hirayama, K., Oshima, H., Yamashita, A., Sakatani, K., Yoshino, A., and Katayama, Y. (2016). Neuroprotective effects of silymarin on ischemia-induced delayed neuronal cell death in rat hippocampus. Brain Res. 1646, 297-303. doi: 10.1016/ j.brainres.2016.06018

Holler, C., Taylor, G., McEachin, Z., Deng, Q., Watkins, W., Hudson, K., et al. (2016). Trehalose upregulates progranulin expression in human and mouse models of grp haploinsufficiency: A novel therapeutic lead to treat frontotemporal dementia. Mol. Neurodegener. 11:46. doi: 10.1186/s13024-0160114-3

Hornedo-Ortega, R., Cerezo, A., de Pablos, R., Krisa, S., Richard, T., GarciaParrilla, M., et al. (2018). Phenolic compounds characteristic of the Mediterranean Diet in mitigating microglia-mediated neuroinflammation. Front. Cell. Neurosci. 12:373. doi: 10.3389/fncel.2018.00373

Howes, M., Perry, N., Vasquez-Londono, C., and Perry, E. (2020). Role of phytochemicals as nutraceuticals for cognitive functions affected in aging. $\mathrm{Br}$. J. Pharmacol. 177, 1294-1315. doi: 10.1111/bph.14898

Hu, J., Han, H., Cao, P., Yu, W., Yang, C., Gao, Y., et al. (2017). Resveratrol improves neuron protection and functional recovery trough enhancement of autophagy after spinal cord injury in mice. Am. J. Transl. Res. 9, 4607-4616.

Hussain, G., Rasul, A., Anwar, H., Aziz, N., Razzaq, A., Wei, W., et al. (2018). Role of plant derived alkaloids and their mechanism in neurodegenerative disorders. Int. J. Biol. Sci. 14, 341-357. doi: 10.7150/ijbs.23247s

Jaroonwitchawan, T., Chaicharoenaudomrung, N., Namkaew, J., and Noisa, P. (2017). Curcumin attenuates paraquat-induced cell death in human neuroblastoma cells through modulating oxidative stress and autophagy. Neurosci. Lett. 636, 40-47. doi: 10.1016/j.neulet.2016.10.050

Jiang, W., Wei, W., Gaertig, M., Li, S., and Li, X. (2015). Therapeutic effect of berberine on Hungtington's disease transgenic mouse model. PLoS One 10:e0134142. doi: 10.1371/journal.pone.0134142

Jung, S., Choe, S., Woo, H., Jeong, H., An, H., Ryu, H., et al. (2020). Autophagic death of neural stem cells mediates chronic-stress-induced decline of adult hippocampal neurogenesis and cognitive deficits. Autophagy 16, 512-530. doi: $10.1080 / 15548627.2019 .1630222$

Kaushik, S., and Cuervo, A. (2018). The coming of age of chaperone-mediated autophagy. Nat. Rev. Mol. Cell Biol. 19, 365-381. doi: 10.1038/s41580-0180001-6

Kennedy, D., and Wightman, E. (2011). Herbal extracts and phytochemicals: plant secondary metabolites and the enhancement of human brain function. $A d v$. Nutr. 2, 32-50. doi: 10.3945/an.110.000117

Khalifeh, M., Barreto, G., and Sahebkar, A. (2019). Trehalose as a promising therapeutic candidate for the treatment of Parkinson's disease. Br. J. Pharmacol. 176, 1173-1189. doi: 10.1111/bph.14623

Kiechl, S., Pechlaner, R., Willeit, P., Notdurfter, M., Paulweber, B., and Willeit, K. (2018). Higher spermidine intake is linked to lower mortality: a prospective population-based study. Am. J. Clin. Nutr. 108, 371-380. doi: 10.1093/ajcn/ nqy 102

Kim, H., Cho, M., Shim, W., Kim, J., Jeon, E., Kim, D., et al. (2017). Deficient autophagy in microglia impairs synaptic pruning and causes social behavioural defects. Mol. Psych. 22, 1576-1584. doi: 10.1038/mp.2016.103

Komatsu, M., Waguri, S., Chiba, T., Murata, S., Iwata, J., Tanida, I., et al. (2006). Loss of autophagy in the central nervous system causes neurodegeneration in mice. Nature 441, 880-884. doi: 10.1038/nature04723

Koronyo-Hamaoui, M., Koronyo, Y., Ljubimov, A., Miller, C., Ko, M., Black, K., et al. (2011). Identification of amyloid plaques in retinas from Alzheimer's patients and noninvasive in vivo optical imaging of retinal plaques in a mouse model. Neuroimage 54, S204-S217. doi: 10.1016/j.neuroimaging.2010.06.020

Kou, X., and Chen, N. (2017). Resveratrol as a natural autophagy regulator for prevention and treatment of Alzheimer's disease. Nutrients 9:927. doi: 10.3390/ nu909027

Krols, M., Van Isterdael, G., Asselbergh, B., Kremer, A., Lippens, S., Timmerman, V., et al. (2016). Mitochondria-associated membranes as hubs for neurodegeneration. Acta Neuropathol. 13, 505-523. doi: 10.1007/s00401-015-1528-7

Kuang, H., Tan, C., Tian, H., Liu, L., Yang, M., Hong, F., et al. (2019). Exploring the bi-directional relationship between autophagy and Alzheimer's disease. CNS Neurosci. Ther. 26, 155-166. doi: 10.1111/cns.13216

Kuang, L., Cao, X., and Lu, Z. (2017). Baicalein protects against rotenone-induced neurotoxicity through induction of autophagy. Biol. Pharm. Bull. 40, 15371543. doi: 10.1248/bpb.b17-00392

Kulkarni, A., Chen, J., and Maday, S. (2018). Neuronal autophagy and intercellular regulation of homeostasis in the brain. Curr. Opin. Neurobiol. 51, 29-36. doi: 10.1016/j.conb.2018.02.008

Lachance, V., Wang, Q., Sweet, E., Choi, I., Cai, C., Zhuang, X., et al. (2019). Autophagy protein NRBF2 has reduced expression in Alzheimer's brains and modulates memory and amyloid-beta homeostasis in mice. Mol. Neurodegen. 14:43. doi: 10.1186/s1304-019-0342-4

Laredo, F., Plebanski, J., and Tedeschi, A. (2019). Pericytes: Problems and Promises for CNS repair. Front. Cell. Neurosci. 13:546. doi: 10.3389/fncel.2019.00546

Lauretti, E., Iuliano, L., and Pratico', D. (2017). Extra-virgin olive oil ameliorates cognition and neuropathology of the 3xTg mice: role of autophagy. Ann. Clin. Transl. Neurol. 4, 564-574. doi: 10.1002/acn3.431

Lauretti, E., Neuov, M., Dincer, O., Iuliano, L., and Pratico', D. (2020). Extra virgin olive oil improves synaptic activity, short-term plasticity, memory and neuropathology in a taupathy model. Aging Cell 19:e13076. doi: 10.1111/acel. 13076

Lee, A., Hirabayashi, Y., Kwon, S., Lewis, T., and Polleux, F. (2018). Emerging roles of mitochondria in synaptic transmission and neurodegeneration. Curr. Opin. Physiol. 3, 82-93. doi: 10.1016/j.cophys.2018.03.009

Lee, H. (2019). Mechanisms and disease implications of sirtuin-mediated autophagic regulation. Exp. Mol. Med. 51:102.

Lee, H., Yoon, Y., and Lee, S. (2018). Mechanism of neuroprotection by trehalose: controversy surrounding autophagy induction. Cell Death Dis. 9:712. doi: 10. 1038/s41419-018-0749-9

Leong, Y., Ng, K., Chye, S., Ling, A., and Koh, R. (2020). Mechanisms of action of amyloid-beta and its precursor protein in neuronal cell death. Metabol. Brain Dis. 35, 11-30. doi: 10.1007/s11011-019-00516-y

Li, I., Lu, Y., Nie, J., Xu, Y., Zhang, W., Yang, W., et al. (2017). Dendrobium nobile Lindl alkaloid a novel autophagy inducer, protects against axonal degeneration induced by Abeta25-35 in hippocampal neurons in vitro. CNS Neurosci. Ther. 23, 329-340. doi: 10.111/cns.12678

Li, P., Ma, K., Wu, H., Wu, Y., and Li, B. (2017). Isoflavones induce BEX2dependent autophagy to prevent ATR-induced neurotoxicity in SH-SY5Y cells. Cell Physiol. Biochem. 43, 1866-1879. doi: 10.1159/000484075

Li, W., Nie, T., Xu, H., Yang, J., Yang, Q., and Mao, Z. (2019). Chaperone-mediated autophagy: Advances from bench to bedside. Neurobiol. Dis. 122, 41-48. doi: 10.1016/j.nbd.2018.05.010

Li, X., Song, J., and Dong, R. (2019a). Cubeben induces autophagy via PI3K-AktmTOR pathway to protect primary neurons against amyloid beta in Alzheimer's disease. Cytotechnology 71, 679-686. doi: 10.1007/s10616-019-00313-6

Li, X., Zhang, D., Bai, Y., Xiao, J., Jiao, H., and He, R. (2019b). Ginaton improves neurological function in ischemic stroke rats via inducing autophagy and maintaining mitochondrial homeostasis. Neuropsych. Dis. Treat. 15, 1813-1822. doi: 10.2147/NDT.s205612

Li, Y., Guo, Y., Wang, X., Yu, X., Duan, W., Hong, K., et al. (2015). Trehalose decreases mutant SOD1 expression and alleviates motor deficiency in early but not end-stage amyotrophic lateral sclerosis in a SOD1-G93A mouse model. Neuroscience 298, 12-25. doi: 10.1016/j.neuroscience.2015. 03.061

Liang, J., Zhou, F., Xiong, X., Zhang, X., Li, S., Li, X., et al. (2019). Enhancing the retrograde axonal transport by curcumin promotes autophagic flux in N2a/APP695swe cells. Aging 11, 7036-7050. doi: 10.18632/aging. 102235 
Lie, P., and Nixon, R. (2019). Lysosome trafficking and signalling in health and neurodegenerative diseases. Neurobiol. Dis. 122, 94-105. doi: 10.1016/j.nbd. 2018.05.015

Lieberman, O., Frier, M., McGuirt, A., Griffey, C., Rafkian, E., Yang, M., et al. (2020). Cell-type-specific regulation of neuronal intrinsic excitability by macroautophagy. eLife 9:e50843. doi: 10.7554/eLife.50843

Lieberman, O., McGuirt, A., Tang, G., and Sulzer, D. (2019). Roles for neuronal and glial autophagy in synaptic pruning during development. Neurobiol. Dis. 122, 49-63. doi: 10.1016/j.nbd.2018.04.017

Lieberman, O., and Sulzer, D. (2019). The synaptic autophagy cycle. J. Mol. Biol. 432, 2589-2604. doi: 10.1016/j.jmb.2019.12.028

Lin, L., Li, C., Zhang, D., Yuan, M., Chen, C., and Li, M. (2020). Berberine and curcumin on improving cognitive function in an Alzheimer's disease mouse model. Neurochem. Res. 45, 1130-1141. doi: 10.1007/s1106402002992-6

Lin, T., Chen, S., Chuang, Y., Lin, H., Huang, C., Chuang, J., et al. (2014). Resveratrol partially prevents rotenone-induced neurotoxicity in dopaminergic 5H-SY5Y cells through induction of heme oxygenase-1 dependent autophagy. Int. J. Mol. Sci. 15, 1625-1646. doi: 10.3390/ijms15011625

Lin, T., Lin, K., Chen, S., Liou, C., Chuang, Y., Lin, H., et al. (2019). The overcrowded crossroads: mitochondria, alpha-synuclein, and the endolysosomal system interaction in Parkinson's disease. Int. J. Mol. Sci. 20:5312. doi: $10.3390 /$ ijms 20215312

Ling, S., Polymenidou, M., and Cleveland, D. (2013). Converging mechanisms in ALS and FTD: disrupted RNA and protein homeostasis. Neuron 79, 416-438. doi: 10.1016/j.neuron.2013.07.033

Lipinski, M., Zheng, B., Yan, Z., Py, B., Ng, A., Xavier, R., et al. (2010). Genomewide analysis reveals mechanisms modulating autophagy in normal brain aging and in Alzheimer's disease. PNAS 107, 14164-14169. doi: 10.1073/pnas. 1009485107

Liu, C., Yin, H., Gao, J., Xu, X., Zhang, T., and Yang, Z. (2016). Leonurine ameliorates cognitive dysfunction via antagonizing excitotoxic glutamate insults and inhibiting autophagy. Phytomedicine 23, 1638-1646. doi: 10.1016/ j.phymed.2016.10.005

Liu, J., and Li, L. (2019). Targeting autophagy for the treatment of Alzheimer's disease: Challenges and Opportunities. Front. Mol. Neurosci. 12:203. doi: 10. 3389/fnmol.2019.00203

Liu, Y., Zhou, H., Gong, Y., Yuan, G., Chen, L., and Liu, J. (2019). Quercetinmodified gold-palladium nanoparticles as a potential autophagy inducer for the treatment of Alzheimer's disease. J. Colloid. Interface Sci. 552, 388-400. doi: 10.1016/j.jcis.2019.05.066

Luan, Y., Ren, X., Zheng, W., Zeng, Z., Guo, Y., Hou, Z., et al. (2018). Chronic caffeine treatment ttprotects against $\alpha$-synucleinopathy by reestablishing autophagy activity in the mouse striatum. Front. Neurosci. 12:301. doi: 10.3389/ fnins.2018.00301

Madeo, F., Bauer, M., Carmona-Gutierrez, D., and Kroemer, G. (2019). Spermidine: a physiological autophagy inducer acting as an anti-aging vitamin in humans? Autophagy 15, 165-168. doi: 10.1080/15548627.2018.1530929

Maiti, P., Rossignol, J., and Dunbar, G. (2017). Curcumin modulates molecular chaperones and autophagy-lysosomal pathways in vitro after exposure to $\mathrm{A} \beta 42$. J Alzheimers Dis. Parkinsonism 7:299. doi: 10.4172/2161-0460.1000299

Maiuri, M., and Kroemer, G. (2019). Therapeutic modulation of autophagy: which disease comes first? Cell Death Diff. 26, 680-689. doi: 10.1038/s41418-0190290-0

Malampati, S., Song, J., Tong, B., Nalluri, A., Yang, C., Wang, Z., et al. (2020). Targeting aggrephagy for the treatment of Alzheimer's disease. Cells 9:311. doi: $10.3390 /$ cells 9020311

Malik, B., Maddison, D., Smith, G., and Peters, O. (2019). Autophagic and endolysosomal dysfunction in neurodegenerative disease. Mol. Brain 12:100. doi: 10.1186/s13041-019-0504-x

Manap, A., Vijayabalan, S., Madhavan, P., Chia, Y., Arya, A., Wong, E., et al. (2019). Bacopa monnieri, a neuroprotective lead in Alzheimer Disease: a review on its properties, mechanisms of action, and preclinical and clinical studies. Drug Target Insights 13:1177392819866412. doi: 10.1177/117739281986 6412

Mariňo, G., Madeo, F., and Kroemer, G. (2011). Autophagy for tissue homeostasis and neuroprotection. Curr. Opin. Cell Biol. 23, 198-206. doi: 10.1016/j.ceb.2010. 10.001
Martinez-Vicente, M., Talloczy, Z., Wong, E., Tang, G., Koga, H., Kaushik, S., et al. (2010). Cargo recognition failure is responsible for inefficient autophagy in Hungtington's disease. Nat. Neurosci. 13, 567-576. doi: 10.1038/nn.2528

Matias, I., Mogado, J., and Carvalho Alcantara-Gomez, F. (2019). Astrocyte heterogeneity: Impact to brain aging and disease. Front. Aging Neurosci. 11:59. doi: 10.3389/fnagi.2019.00059

Mazzanti, G., and Di Giacomo, S. (2016). Curcumin and resveratrol in the management of cognitive disorders: what is the clinical evidence? Molecules 21:1243. doi: $10.3390 /$ molecules 21091243

Menzies, F., Fleming, A., Caricasole, C., Bento, S., Andrews, A., Ashkenazi, A., et al. (2017). Autophagy and neurodegeneration: pathogenic mechanisms and therapeutic opportunities. Neuron 93, 1015-1034. doi: 10.1016/j.neuron.2017. 01.022

Misgeld, T., and Schwarz, T. (2017). Mitostasis in neurons: maintaining mitochondria in an extended cellular architecture. Neuron 96, 651-666. doi: 10.1016/j.neuron.2017.09055

Mizushima, N. (2018). Perspective. A brief history of autophagy from cell biology to physiology and disease. Nat. Cell Biol. 20, 521-527. doi: 10.1038/s41556-0180092-5

Mogk, A., and Bukau, B. (2017). Role of sHSPs in organizing cytosolic protein aggregation and disaggregation. Cell Stress Chaperones 22, 493-502. doi: 10. 1007/s12192-017-0762-4

Moon, J., Lee, J., Park, J., Kim, S., Lee, Y., Kang, S., et al. (2014). Caffeine prevents human prion-protein-mediated neurotoxicity through the induction of autophagy. Int. J. Mol. Med. 34, 553-558. doi: 10.3892/ijms.2014.1814

Morel, E., Mehrpour, M., Botti, J., Dupont, N., Hamai, A., Nascimbeni, A., et al. (2017). Autophagy: a druggable process. Ann. Rev. Pharmacol. Toxicol. 57, 375-398. doi: 10.1146/annurev-pharmatox-010716-104936

Morimoto, R., and Cuervo, A. (2014). Proteostasis and the aging proteome in health and disease. J. Gerontol. Ser A Biol. Sci. Med. Sci. 69, S33-S38. doi: 10.1093/Gerona/glu049

Morishita, H., and Mizushima, N. (2019). Diverse cellular roles of autophagy. Ann. Rev. Cell Dev. 35, 453-475. doi: 10.1146/annurev-cellbio-100818-125300

Mputhia, Z., Hone, E., Tripathi, T., Sargeant, T., Martins, R., and Bharadwaj, P. (2019). Autophagy modulation as a treatment of amyloid diseases. Molecules 24:3372. doi: $10.3390 /$ molecules 24183372

Muñoz-Esparza, N., Latorre-Moratalla, M., Comas-Basté, O., Toro-Funes, N., Veciana-Nogues, M., and Vidal-Carou, C. (2019). Polyamines in Food. Front. Nutr 6:108. doi: 10.3389/fnut.2019.00108

Naoi, M., Shamoto-Nagai, M., and Maruyama, W. (2019). Neuroprotection of multifunctional phytochemicals as novel therapeutic strategy for neurodegenerative disorders: antiapoptotic and antiamyloidogenic activities by modulation of cellular signal pathways. Future Neurol. 14:FNL9. doi: 10.2217/fnl-2018-0028

Negrete-Hurtado, A., Overhoff, M., Bera, S., De Buruyckere, E., Schatzmuller, K., Kye, M., et al. (2020). Autophagy lipidation machinery regulates axonal microtubule dynamics but is dispensable for survival of mammalian neurons. Nat. Commun. 11:1535. doi: 10.1038/s41467-020-15287-9

Nikoletopoulou, V., Papandreou, M., and Tavernarakis, N. (2015). Autophagy in the physiology and pathology of the central nervous system. Cell Death Diff. 22, 398-407. doi: 10.1038/cdd.2014.204

Nixon, R. (2013). The role of autophagy in neurodegenerative disease. Nat. Med. 19, 983-997. doi: 10.1038/nm3232

Noda, S., Sato, S., Fukuda, T., Tada, N., Uchiyama, Y., Tanaka, K., et al. (2020). Loss of Parkin contributes to mitochondrial turnover and dopaminergic neuronal loss in aged mice. Neurobiol. Dis. 136:104717. doi: 10.1016/j.nbd.2019.104717

Nopparat, C., Sinjanakhom, P., and Govitrapong, P. (2017). Melatonin reverses $\mathrm{H} 2 \mathrm{O} 2$-induced senescence in SH-SY5Y cells by enhancing autophagy via sirtuin 1 deacetylation of the RelA/p65 subunit of NF-kB. J. Pineal Res. 63:28295567. doi: $10.1111 /$ jpi.12407

Oshima, M., Seki, T., Kurauchi, Y., Hisatsune, A., and Katsuki, H. (2019). Reciprocal regulation of chaperone-mediated autophagy /microautophagy and exosome release. Biol. Pharm. Bull. 42, 1394-1401. doi: 10.1248/bpb.b19-00316

Palikaras, K., Lionaki, E., and Tavernarakis, N. (2018). Mechanisms of mitophagy in cellular homeostasis, physiology and pathology. Nat. Cell Biol. 20, 1013-1022. doi: 10.1038/s41556-0180176-2

Palikaras, K., and Tavernarakis, N. (2020). Regulation and roles of mitophagy at synapses. Mech. Ageing Dev. 187:111216. doi: 10.1016/j.mad.2020.111216 
Palmieri, M., Pal, R., Nelvagal, H., Lotfi, T., Stinnett, G., Seymour, M., et al. (2017). mTORC1-independent TFEB activation via Akt inhibition promotes cellular clearance in neurodegenerative storage diseases. Nat. Commun. 8:14338. doi: $10.1038 /$ comms 14338

Park, G., Kusuma, I., and Kim, Y. (2018). Multiple bioactivities of traditional medicinal herbs for treatment of neurodegenerative diseases. Evid Based Compl. Alt. Med. 2018:3075458. doi: 10.1155/2018/3075458

Park, H., Kang, J., and Lee, S. (2020). Autphagy in neurodegenerative diseases: a hunter for aggregates. Int. J. Mol. Sci. 21:3369. doi: 10.3390/ijms20193369

Peng, W., Minakaki, G., Nguyen, M., and Krainc, D. (2019). Preserving lysosomal function in the aging brain: insights from neurodegeneration. Neurotherapeutics 16, 611-634. doi: 10.1007/s13311-019-00742-3

Perez-Hernandez, J., Zaldivar-Machorro, V., Villanueva-Porras, D., Vega-Avila, E., and Chavarria, A. (2016). A potential alterative against neurodegenerative diseases: Phytodrugs. Oxid. Med. Cell. Long. 2016:8378613. doi: 10.1155/2016/ 8378613

Perrone, L., Squillano, T., Napolitano, F., Terracciano, C., Sampaolo, S., and Melone, M. (2019). The autophagy signaling pathway: a potential multifunctional therapeutic target of curcumin in neurological and neuromuscular diseases. Nutrients 11:1881. doi: 10.3390/nu11081881

Pickford, F., Masliah, E., Britschgi, M., Lucin, K., Narasimhan, R., Jager, P., et al. (2008). The autophagy-related protein beclin 1 shows reduced expression in early Alzheimer disease and regulates amyloid beta accumulation in mice. J. Clin. Invest. 118, 2190-2199. doi: 10.1172/JCI33585

Pietrocola, F., Lachkar, S., Enot, D., Niso-Santano, M., Bravo-San Pedro, J., Sica, V., et al. (2015). Spermidine induces autophagy by inhibiting the acetyltransferase EP300. Cell Death Diff. 22, 509-516. doi: 10.1038/cdd.2014.215

Pineda-Ramirez, N., Alquisiras-Burgos, I., Ortiz-Plata, A., Ruiz-Tachiquin, M., Espinoza-Rojo, M., and Aguilera, P. (2020). Resveratrol activates neuronal autophagy through AMPK in the ischemic brain. Mol. Neurobiol. 57, 10551069. doi: 10.1007/s12035-019-01803-6

Plaza-Zabala, A., Sierra-Torre, V., and Sierra, A. (2017). Autophagy and microglia: Novel partners in neurodegeneration and aging. Int. J. Mol. Sci. 18:598. doi: $10.3390 /$ ijms 1803598

Pohl, F., and Lin, P. (2018). The potential use of plant natural products and plant extracts with antioxidant properties for the prevention/treatment of neurodegenerative diseases: in vitro, in vivo and clinical studies. Molecules 23:3283. doi: 10.3390/molecules23123283

Porquet, D., Griñan-Ferré, C., Ferrer, I., Camins, A., Sanfelin, C., del Valle, J., et al. (2014). Neuroprotective role of trans-resveratrol in a murine model of familial Alzheimer's disease. J. Alzheimer's Diease 42, 1209-1220. doi: 10.3233/ JAD- 140444

Portbury, S., Hare, D., Sgambelloni, C., Perronnes, K., Portbury, A., Finkelstein, D., et al. (2017). Trehalose improves cognition in the transgenic Tg2576 mouse model of Alzheimer's disease. J Alzheimer's Disease 60, 549-560. doi: 10.3233/ JAD- 170322

Potì, F., Sarti, D., Spaggiari, G., Zimetti, F., and Zanotti, I. (2019). Polyphenol health effects on cardiovascular and neurodegenerative disorders: a review and meta-analysis. Int. J. Mol. Sci. 20:351. doi: 10.3390/ijms 2020351

Prasanth, M., Sivamaruthi, B., Chaiyasut, C., and Tencomnao, T. (2019). A review of the role of green tea (Camelia sinensis) in antiphotoaging, stress resistance, neuroprotection, and autophagy. Nutrients 11:474. doi: 10.3390/nu11020474

Prieto-Dominguez, N., Garcia-Mediavilla, M., Sanchez-Campos, S., Mauriz, J., and Gonzales-Gallego, J. (2018). Autophagy as a molecular target of flavonoids underlying the protective effects in human diseases. Curr. Med. Chem. 25, 814-838. doi: 10.2174/092986732466617091812515

Quintans, J., Shanmugam, S., Heimfarth, L., Araujo, A., Almeida, J., Picot, L., et al. (2019). Monoterpenes modulating cytokines-A review. Food Chem. Toxicol. 123, 233-257. doi: 10.1016/j

Rahman, M., Rahman, R., Zaman, T., Uddini, S., Islam, R., Abdel-Daim, M., et al. (2020). Emerging potential of naturally occurring autophagy modulators against neurodegeneration. Curr. Pharmaceutic. Des. 7, 772-779. doi: 10.2174/ 1381612826666200107142541

Reddy, P., and Oliver, D. (2019). Amyloid beta and phosphorylated tau-induced defective autophagy and mitophagy in Alzheimer's disease. Cells 8:E488. doi: $10.3390 /$ cells 8050488
Rekha, K., and Sivakamasundari, R. (2018). Geraniol protects against the protein and oxidative stress induced by rotenone in an in vitro model of Parkinson's disease. Neurochem. Res. 43, 1947-1962. doi: 10.1007/s11064-018-2617-5

Renaud, J., and Martinoli, M. (2019). Considerations for the use of polyphenols as therapies in neurodegenerative diseases. Int. J. Mol. Sci. 20:1883. doi: 10.3390/ ijms 20081883

Rigacci, S., Miceli, C., Nediani, C., Berti, A., Cascella, R., Pantano, D., et al. (2015). Oleuropein aglycone induces autophagy via the AMPK/mTOR signalling pathway: a mechanistic insight. Oncotarget 6:35344. doi: 10.18632/oncotarget. 6119

Rusmini, P., Cortese, K., Crippa, V., Cristofani, R., Cicardi, M., Ferrari, V., et al. (2019). Trehalose induces autophagy via lysosomal-mediated TFEB activation in models of motoneuron degeneration. Autophagy 4, 631-651. doi: 10.1080/ 15548627.2018.1535292

Russo, R., Cassiano, M., Ciociaro, A., Adornetto, A., Varano, G., Chiappini, C., et al. (2014). Role of D-Limonene in autophagy induced by bergamot essential oil in SH-SY5Y neuroblastoma cells. Plos One 9:e113682. doi: 10.1371/journal.pone. 0113682

Ryan, T., Bamm, V., Stukel, M., Coackley, C., Humphries, K., Jamieson-Williams, R., et al. (2018). Cardiolipin exposure on the outer mitochondrial membrane modulates $\alpha$-synuclein. Nat. Commun. 9:817. doi: 10.1038/s41467-01803241-9

Salehi, B., Mishra, A., Nigam, M., Sener, B., Kilic, M., Sharifi-Rad, M., et al. (2018). Resveratrol: A double-edged sword in health benefits. Biomedicines 6:91. doi: 10.3390/biomedicines6030091

Sanchez-Martin, P., and Komatsu, M. (2018). P62/SQSTM1-steering the cell through health and disease. J. Cell Sci. 131:jcs222836. doi: 10.1242/jcs.222836

Sasazawa, Y., Sato, N., Umezawa, K., and Simizu, S. (2015). Conophylline protects cells in cellular models of neurodegenerative diseases by inducing mammalian target of rapamycin (mTOR)-independent autophagy. J. Biol. Chem. 290, 61686178. doi: 10.1074/jbc.M114.606293

Sato, M., Seki, T., Konno, A., Hirai, H., Kurauchi, Y., Hisatsune, A., et al. (2019). Rapamycin activates mammalian microautophagy. J. Pharmacol. Sci. 140, 201204. doi: 10.1016/j.phs.2019.05.007

Schepers, M., Martens, N., Tiane, A., Vanbrabant, K., Liu, H., Lutjohann, D., et al. (2020). Edible seaweed-derived constituents: an undisclosed source of neuroprotective compounds. Neural Regen. Res. 15, 790-795. doi: 10.4103/ 1673-5374.268894

Schwarz, C., Stekovic, S., Wirth, M., Benson, G., Royer, P., Sigrist, S., et al. (2018). Safety and tolerability of spermidine supplementation in mice and older adults with subjective cognitive decline. Aging 10, 19-33. doi: 10.18632/aging.101354

Scrivo, A., Bourdenx, M., Pampliego, O., and Cuervo, A. (2018). Selective autophagy as a potential therapeutic target for neurodegenerative disorders. Lancet Neurol. 17, 802-815. doi: 10.1016/S1474-4422(18)30238-2

Shakeri, A., Cicero, A., Panah, Y., and Sahebkar, A. (2019). Curcumin: a naturally occuring autophagy modulator. J. Cell Physiol. 234, 5643-5654. doi: 10.1002/ jcp. 27404

Shi, L., Liang, F., Zheng, J., Zhou, K., Chen, S., Yu, J., et al. (2018). Melatonin regulates apoptosis and autophagy via ROS-MST1 pathway in sub-arachnoid hemorrage. Front. Mol. Neurosci. 11:93. doi: 10.3389/fnmol.2018.00093

Shukla, M., Chinchalongporn, V., Govitrapong, P., and Reiter, R. (2019). The role of melatonin in targeting cell signalling pathways in neurodegeneration. Ann. N Y Acad. Sci. 1443, 75-96. doi: 10.1111/nyas.14005

Song, J., Sun, Y., Peluso, I., Zeng, Y., Yu, X., Wang, M., et al. (2016). A novel curcumin analog binds to and activates TFEB in vitro and in vivo independent of mTOR inhibition. Autophagy 12, 1372-1389. doi: 10.1080/15548627.2016. 1179404

Stavoe, A., and Holzbaur, E. (2019). Axonal autophagy: Mini-review for autophagy in the CNS. Neurosc. Lett. 697, 17-23. doi: 10.1016/j.neulet.2018.03.025

Steiner, G., Bensoussan, A., Liu, J., Hohenberg, M., and Chang, D. (2018). Study protocol for randomized, double-blind, placebo-controlled 12 week pilot phase II trial of sailuotong (SLT) for cognitive function in older adults with mild cognitive impairment. Trials 19:522. doi: 10.1186/s13063-018-2912-0

Stevens, B. (2003). Glia-much more than the neuron's side-kick. Curr. Biol. 13, R469-R472. doi: 10.1016/S0960-9822(03)00404-4

Strohm, L., and Behrends, C. (2019). Glia-specific autophagy dysfunction in ALS. Semin. Cell Dev. Biol 99, 172-182. doi: 10.1016/j.semcdb.2019.05.024 
Suomi, F., and Mc Williams, T. (2020). Autophagy in the mammalian nervous system: a primer for neuroscientists. Neuronal Signaling 3:NS20180134. doi: 10.1042/NS20180134

Tan, S., Yu, C., Sim, Z., Low, Z., Lee, B., See, F., et al. (2019). Pomegranate activates TFEB to promote autophagy-lysosomal fitness and mitophagy. Sci. Rep. 9:727. doi: 10.1038/s41598-018-37400

Tanaka, K., and Matsuda, N. (2014). Proteostasis and neurodegeneration: The roles of proteasomal degradation and autophagy. BBA-Mol. Cell Res. 1843, 197-204. doi: 10.1016/j.bbamcr.2013.03.012

Taylor, R., Berendzen, K., and Dillin, A. (2014). Systemic stress signalling: Understanding the cell-non-autonomous control of proteostasis. Nat. Rev. Mol. Cell Biol. 15, 211-217. doi: 10.1038/nrm3752

Thellung, S., Corsaro, A., Nizzari, M., Barbieri, F., and Florio, T. (2019). Autophagy activator drugs: a new opportunity in neuroprotection from misfolded protein toxicity. Int. J. Mol. Sci. 20:901. doi: 10.3390/ijms200 40901

Tian, J., Liu, Y., and Chen, K. (2017). Ginkgo biloba extract in vascular protection: molecular mechanisms and clinical applications. Curr. Vasc. Pharmacol. 15, 532-548. doi: 10.2174/1570161115666170713 095545

Tien, N., Karaca, I., Tamboli, I., and Walter, J. (2016). Trehalose alters subcellular trafficking and the metabolism of the Alzheimer -associated amyloid precursor protein. J. Biol. Chem. 291, 10528-10540. doi: 10.1074/jbc.H116. 719286

Tomoda, T., Yang, K., and Sawa, A. (2019). Neuronal autophagy in synaptic functions and psychiatric disorders. Biol. Psych. 87, 787-796. doi: 10.1016/j. biopsych.2019.07.018

Tripathi, M., Rajput, C., Mishra, S., Rasheed, M., and Singh, M. (2019). Malfunctioning of chaperone-mediated autophagy in Parkinson's disease: Feats, Constraints, and Flaws of modulators. Neurotoxicity Res. 35, 260-270. doi: 10.1007/s12640-018-9917-z

Truban, D., Hou, X., Caulfield, T., Fiesel, F., and Springer, W. (2017). PINK1, Parkin, and Mitochondrial quality control: What can we learn about Parkinson's disease pathobiology? J. Parkinson's Dis. 7, 13-29. doi: 10.3222/JPD160989

Tsao, R. (2010). Chemistry and biochemistry of dietary polyphenols. Nutrients 2, 1231-1246. doi: 10.3390/nu2121231

Umezawa, K., Kojima, I., Simizu, S., Lin, Y., Fukatsu, H., Koide, N., et al. (2018). Therapeutic activity of plant-derived alkaloid conophylline on metabolic syndrome and neurodegenerative diseases models. Hum. Cell 31, 95-101. doi: 10.1007/s13577-017-0196-4

Ungelenk, S., Moayed, F., Ho, C., Grousl, T., Scharf, A., Mashaghi, A., et al. (2016). Small heat shock proteins sequester misfolding proteins in near-native conformation for cellular protection and efficient refolding. Nat. Commun. 7:13673. doi: $10.1038 /$ ncomms 13673

Vauzour, D., Camprubi-Robles, M., Miquel-Kergoat, S., Andres-Lacueva, C., Banati, D., Barberger-Gateau, P., et al. (2017). Nutrition for the ageing brain: Towards evidence for an optimal diet. Ageing Res. Rev. 35, 222-240. doi: 10. 1016/j.arr.2016.09.010

Vidoni, C., Secomandi, E., Castiglioni, A., Melone, M., and Isidoro, C. (2018). Resveratrol protects neuronal-like cells expressing mutant huntingtin from dopamine toxicity by rescuing ATG4-mediated autophagosome formation. Neurochem. Int. 117, 174-187. doi: 10.1016/j.neuint.2017. 05.013

Voulgaropoulou, S., Vanamelsvoort, T., Prickaerts, J., and Vingerhoets, C. (2019). The effect of curcumin on cognition in Alzheimer's disease and healthy aging: a systematic review of preclinical and clinical studies. Brain Res. 1725:146476. doi: 10.1016/j.brainres.2019.146476

Wang, C., Zhang, X., Teng, Z., Zhang, T., and Li, Y. (2014). Downregulation of PI3K/Akt/mTOR signalling pathway in curcumin-induced autophagy in APP/PS1 double transgenic mice. Eur. J. Pharmacol. 740, 312-320. doi: 10.1016/ j.ejphar.2014.06.051

Wang, D., Li, S., Wu, W., Zhu, X., Wang, Y., and Yuan, H. (2014). Effects of long-term treatment with quercetin on cognition and mitochondrial function in a mouse model of Alzheimer's disease. Neurochem. Res. 39, 1533-1543. doi: 10.1007/s11064-014-1343-x

Wang, H., Jiang, T., Li, W., Gao, N., and Zhang, T. (2018). Resveratrol attenuates oxidative damage trough activating mitophagy in an in vitro model of
Alzheimer's disease. Toxicol. Lett. 282, 100-108. doi: 10.1016/j.toxlet.2017.10. 021

Wang, H., Liu, C., Mei, X., Cao, Y., Guo, Z., Yuan, Y., et al. (2017). Berberine attenuated pro-inflammatory factors and protect against neuronal damage via triggering oligodendrocyte autophagy - in spinal cord injury. Oncotarget 8 , 98312-98321. doi: 10.18632/oncotarget.21203

Wang, J., Qi, Q., Feng, Z., Zhang, X., Huang, B., Chen, A., et al. (2016). Berberine induces autophagy in glioblastoma by targeting the AMPK/mTOR/ULK1 pathway. Oncotarget 7, 66944-66958. doi: 10.18632/oncotarget. 11396

Wang, J., and Xu, C. (2020). Astrocytes autophagy in aging and neurodegenerative disorders. Biomed. Pharmacother. 122:109691. doi: 10.1016/j.biopha.2019. 109691

Wang, N., Wang, H., Li, L., Li, Y., and Zhang, R. (2020). $\beta$-asarone inhibits amyloid- $\beta$ by promoting autophagy in a cell model of Alzheimer's disease. Front. Pharmacol. 10:1529. doi: 10.3389/fphar.2019. 01529

Wang, P., Jiang, L., Zhou, N., Zhou, H., Liu, H., Zhao, W., et al. (2018). Resveratrol ameliorates autophagic flux to promote functional recovery in rats after spinal cord injury. Oncotarget 9, 8427-8440. doi: 10.18632/oncotarget. 23877

Wilhelm, B., Mandad, S., Truckenbrodt, S., Krohnert, K., Schafer, C., Rammner, B., et al. (2014). Composition of isolated synaptic boutons reveals the amounts of vesicle trafficking proteins. Science 344, 1023-1028. doi: 10.1126/science. 1252884

Wu, H., Chen, S., Ammar, A., Xu, J., Wu, Q., Pan, K., et al. (2015). Crosstalk between macroautophagy and chaperone-mediated autophagy: Implications for the treatment of neurological diseases. Mol. Neurobiol. 52, 1284-1296. doi: 10.1007/s12035-014-8933-0

Wu, Y., Whitens, C., Xu, C., Hayworth, K., Weinberg, R., Hesse, H., et al. (2017). Contacts between the endoplasmic reticulum and other membranes in neurons. PNAS 114, E4859-E4867. doi: 10.1073/pnas.17010 78114

Xie, C., Aman, Y., Adrianse, B., Cader, M., Plun-Favreau, H., Xiao, J., et al. (2020). Culprit or Bystander: Defective mitophagy in Alzheimer's disease. Front. Cell Dev. Biol. 7:391. doi: 10.3388/fcell.2019.00391

Xie, J., Liang, J., and Chen, N. (2019). Autophagy-associated signal pathways of functional foods for chronic diseases. Food Sci. Hum. Wellness 8, 25-33. doi: 10.1016/j.fshw.2019.03.002

Xilouri, M., Brekk, O., Landeck, N., Pitychoutis, P., Papasilekas, T., PapadopoulouDaifoti, Z., et al. (2013). Boosting chaperone-mediated autophagy in vivo mitigates $\alpha$-synuclein-induced neurodegeneration. Brain 136, 2130-2146. doi: 10.1093/brain/awt131

Yang, C., Cai, C., Song, J., Tan, J., Durairajan, S., Iyaswamy, A., et al. (2017). NRBF2 is involved in the autophagic degradation process of APP-CTFs in Alzheimer disease models. Autophagy 13, 2028-2040. doi: 10.1080/15548627. 2017.1379633

Yang, Q., Zheng, C., Cao, J., Cao, G., Shou, P., Lin, L., et al. (2016). Spermidine alleviates experimental autoimmune encephalomyelitis through inducing inhibitory macrophages. Cell Death Differ. 23, 1850-1861. doi: 10.1038/cdd. 2016.71

Yessenkyzy, A., Saliev, T., Zhanaliyeva, H., Masoud, A., Umbayev, B., Sergazy, S., et al. (2020). Polyphenols as caloric-restriction mimetics and autophagy inducers in aging research. Nutrients 12:1344. doi: 10.3390/nu1205 1344

Yoon, Y., Cho, E., Ahn, W., Lee, K., Lee, S., and Lee, H. (2017). Is trehalose an autophagic inducer? Unraveling the roles of non-reducing disaccharides on autophagic flux and alpha-synuclein aggregation. Cell Death Dis. 8:e3091. doi: $10.1038 /$ cddis.2017.501

Yu, D., Li, M., Nie, P., Zhang, Z., and Zhou, Y. (2018). Bcl-2/E1B-19kD-Interacting protein $3 /$ light chain 3 interaction induces mitophagy in spinal cord injury in rats both in vivo and in vitro. J. Neurotrauma. 35, 2183-2194. doi: 10.1089/neu. 2017.5280

Yu, S., Baek, S., Brennan, R., Bradley, C., Park, S., Lee, Y., et al. (2008). Autophagic death of adult hippocampal neural stem cells following insulin withdrawal. Stem Cells 26, 2602-2610. doi: 10.1634/stemcells.2008-0153

Zachari, M., and Gauley, I. (2017). The mammalian ULK1 complex and autophagy initiation. Ess. Biochem. 61, 585-596. doi: 10.1042/EBC20170021 
Zeng, H., and Sanes, J. (2017). Neuronal cell-type classification: challenges, opportunities and the path forward. Nat. Rev. Neurosci. 18:530. doi: 10.1038/ nrn. 2017.85

Zeng, Q., Siu, W., Li, L., Liang, S., Cao, M., Ma, M., et al. (2019). Autophagy in Alzheimer's disease and promising modulatory effects of herbal medicine. Exp. Gerontol. 119, 100-110. doi: 10.1016/j.exger.2019.01.027

Zhang, L., Fang, Y., Cheng, X., Lian, Y., Zeng, Z., Wu, C., et al. (2018). The potential protective effect of curcumin on amyloid- $\beta-42$ induced cytotoxicity in HT-22 cells. Biomed. Res. Int. 2018:8134902. doi: 10.1155/2018/8134902

Zhang, L., Wang, H., and Fan, Y. (2017). Fucoxanthin provides neuroprotection in models of traumatic brain injury via the Nrf2-ARE and Nrf2-autophagy pathways. Sci. Rep. 7:46763. doi: 10.1038/srep46763

Zhang, X., Chen, J., Ouyang, D., and Lu, J. (2020). Quercetin in animal models of Alzheimer's disease: a systematic review of preclinical studies. Int. J. Mol. Sci. 21:493. doi: 10.3390/ijms2102493

Zhao, H., Chen, S., Gao, K., Zhou, Z., Wang, C., Shen, Z., et al. (2017). Resveratrol protects against spinal cord injury by activating autophagy and inhibiting apoptosis mediated by the SIRT1/AMPK signalling pathway. Neuroscience 348, 241-251. doi: 10.1016/j.neuroscience.2017.02.027

Zholos, A., Moroz, O., and Storozhuk, M. (2019). Curcuminoids and novel opportunities for the treatment of Alzhemeir's disease: Which molecules are actually effective? Curr. Mol. Pharmacol. 12, 12-26. doi: 10.2174/ 1874467211666181012150847

Conflict of Interest: The authors declare that the research was conducted in the absence of any commercial or financial relationships that could be construed as a potential conflict of interest.

Copyright (c) 2020 Stacchiotti and Corsetti. This is an open-access article distributed under the terms of the Creative Commons Attribution License (CC BY). The use, distribution or reproduction in other forums is permitted, provided the original author(s) and the copyright owner(s) are credited and that the original publication in this journal is cited, in accordance with accepted academic practice. No use, distribution or reproduction is permitted which does not comply with these terms. 